\title{
ANÁLISIS DE TRES OBRAS PARA CLARINETE, VIOLA Y PIANO, DE LIDUINO PITOMBEIRA
}

\section{ANALYSIS OF THREE WORKS FOR CLARINET, VIOLA AND PIANO BY LIDUINO PITOMBEIRA}

Karen Johana Correa Suárez ${ }^{* *}$

Correo electrónico: kcorrea1@eafit.edu.co

Artículo recibido: 10-04-2019

Artículo aprobado: 07-05-2019

Este artículo deviene de una investigación doctoral que estudia detalladamente el timbre y las técnicas extendidas en el repertorio para violonchelo de los siglos XX y XXI, titulada "New Directions in the Cello Timbre: Works for Solo Cello and Cello with Electronic Media in the 21st Century by Colombian Composers", desarrollada en la Facultad de Artes de la Universidad de Helsinki.

** Estudiante de Maestría en Música con énfasis en interpretación de la Universidad EAFIT. 


\section{Resumen}

Luego de una búsqueda de repertorio latinoamericano para el conjunto instrumental de clarinete, viola y piano (Correa Suárez \& Sheldrick, 2019), se hace relevante dar conocer a profundidad lo encontrado. Por tal razón, este artículo provee información sobre tres de las obras escritas por un mismo compositor, Liduino Pitombeira (Brasil, 1962). Se incluye un análisis formal y del uso de los instrumentos a lo largo de las obras.

Palabras clave: Compositores latinoamericanos; Clarinete; Liduino Pitombeira; Música de Brasil; Música de cámara; Piano; Viola.

\section{Abstract}

A search for Latin American repertoire for the instrumental ensemble of clarinet, viola and piano has revelated the lack of information and the need for more in-depth study on this topic (Correa Suárez \& Sheldrick, 2019). This article discusses three works by the Brazilian composer Liduino Pitombeira and includes a formal analysis as well as an examination of the use of the instruments throughout the works.

Keywords: Brazilian music, Chamber music, Clarinet, Latin American composers, Liduino Pitombeira, Piano, Viola. 


\section{Introducción}

El compositor brasileño Liduino Pitombeira ha dedicado gran parte de su vida a la composición y a la investigación musical desde diversos puntos de vista, tales como la estructura musical, las relaciones entre música y matemática, y los sistemas de composición musical de otros compositores del siglo xx aplicados a relaciones teóricas avanzadas (Pitombeira, 2015).

En este artículo se presentará el análisis de tres obras para conjunto de clarinete, viola y piano, pero que han sido originalmente instrumentadas para diferentes conjuntos de cámara. El interés principal es la comprensión de la música escrita por este compositor y cómo ella llega a nosotros.

\section{Liduino Pitombeira}

Nació en Russas, estado de Ceará, Brasil, en 1962. Pitombeira es profesor de composición en la Escuela de Música de la Universidad Federal de Río de Janeiro (UFRJ) en Brasil. Realizó sus estudios de pregrado en la Universidad Estatal de Ceará en Brasil, bajo la tutoría de los maestros Vanda Ribeiro Costa, Tarcísio José de Lima e José Alberto Kaplan. Pitombeira recibió su doctorado en composición, con un título menor en Teoría, de la Universidad Estatal de Luisiana (LSU) en mayo de 2004, donde estudió con Dinos Constantinides y Jeffrey Perry (Pitombeira, 2015). La música de Liduino Pitombeira es muy influenciada por músicos como Bela Bartok, Igor Stravinsky, Hermeto Pascoal, Egberto Gismonti y Mozart Camargo Guarnieri. Este último, de influencia muy notable en sus primeras composiciones (Pitombeira, 2019).

Ha publicado artículos sobre composición y teoría musical en varias revistas académicas en Brasil y también ha presentado sus investigaciones sobre teoría de la composición (especialmente relacionadas con sistemas de composición y modelado sistémico) y sobre teoría musical general en conferencias en Brasil y en el extranjero. Recibió numerosos premios de composición en Brasil y Estados Unidos, incluido el primer premio en la Competencia de Composición Camargo Guarnieri, en 1998, con la obra Sinfonía dos 500 anos. También recibió el Premio al Compositor Distinguido del Año, MTNA-Shepherd, en 2003, por su obra Paisajes brasileños Nro.1. Tres piezas más de su serie, Brazilian Landscapes (Nros. 2, 6 y 9), obtuvieron otros primeros premios en los Estados Unidos. La música de Pitombeira ha sido interpretada por la Berliner Philharmonic Wind Quintet y la Orquesta Filarmónica de Poznan, en Europa; la Louisiana Sinfonietta, en Estados Unidos y, en Brasil, por la Orquesta Filarmónica de Espíritu Santo, la Orquesta Sinfónica de la Universidad de São Paulo, la Orquesta Sinfónica de Ribeirão Preto, el Duo Barrenechea, el Dúo Alexander-Soares y la Orquesta Sinfónica del Estado de São Paulo.

Pitombeira es miembro de MusMat, grupo de investigación afiliado al Programa de 
Estudios de Posgrado en Música de la UFRJ, el cual tiene como propósito desarrollar estudios y modelos informáticos relacionados con la música y las matemáticas y sus aplicaciones en los campos de la composición y el análisis musical. También es miembro de la Society of Composers Inc., la Associação Nacional de Pesquisa y Pós-Graduação em Música (ANPPOM) y la College Music Society. Sus piezas han sido publicadas por Peters, Bella Musica, Conners, Alry, RioArte e Irmãos Vitale. Y las grabaciones de sus obras han estado a cargo de Magni, Summit, Centaur, Antes, Filarmonika y Bis.

\subsection{Fantasia sobre a muié rendêra op. $1 f$}

La melodía A muié rendêra, muy popular en Brasil, ${ }^{1}$ posiblemente fue escrita por Virgulino Ferreira da Silva, también conocido como Lampião, una figura legendaria de la tradición del noreste de Brasil.3 Según algunos autores (de Quadros Junior \& Volp, 2005) este tema entra dentro del género del baião, ${ }^{2}$ para cuya ejecución es usual la participación de un tamborero, un acordeonero y un ejecutante de triángulo.

El autor escribió originalmente esta obra, en 1988, para clavicémbalo y viola da gamba, y se convirtió en su op. 1. Esta obra fue escrita para el grupo Syntagma ${ }^{3}$ , al cual perteneció el compositor a partir de su fundación en 1986 y hasta 1998, donde interpretó flautas, laúd, salterio, guitarra y percusión. Durante estos años, el maestro Pitombeira realizó muchos arreglos de música popular y folclórica, ya que este grupo se especializó en la interpretación de música nordestina brasileña al estilo barroco (Pitombeira, 2019). Las versiones de esta obra se enlistan a continuación:

- Op. 001a (1988), para conjunto de flautas de pico y clave.

- Op. 001b (1988), para sexteto de flautas y clavicémbalo.

- Op. 001c (1988), para flauta, orquesta de cuerdas y piano. Estrenada por The Sinfonietta Sextet, bajo la dirección de Márcio Landi, en el Recital Hall de la LSU School of Music, el 14 de enero de 2002.

- Op. 001e (1988), para flauta y piano. Estrenada por Sammy Fuks (flauta), Angela Lima (piano), en el Our Lady of the Lake de la University Music Dept., el 23 de enero de 2005.

1 Virgulino Ferreira da Silva es un personaje popular conocido como Lampião o Volta seca, quien vivía como cangaceiro. Se conoce como cangaceiros a las personas subversivas que vagaban por los campos del nordeste de Brasil entre el siglo XIX y principios del XX, matando o robando por diferentes motivos, ya fuera como justicieros sociales o simplemente por psicopatía.

2 Género musical brasileño, proveniente del lundu africano que fue llevado al nordeste con el nombre de baiano, término que refiere al verbo bailar. Es un género de ritmo binario muy popular en las zonas campesinas y suele contar historias de mujeres trabajadoras (de Quadros Junior \& Volp, 2005). Para mayor ilustración, ver el video de PEAO (2009).

3 Ver el vídeo de BodartPreciosidades (2013). 
- Op. 001f, para clarinete, viola y piano (cfr. Benedetti, 2015).

- Op. 001g, para tres flautas de pico (soprano y dos altos) y clave.

- Op. 001h, para dos flautas, vibráfono y contrabajo.

Todas estas variaciones fueron escritas a partir de las solicitudes de los intérpretes al compositor. A continuación, se analiza la versión para clarinete, viola y piano (op. 001f).

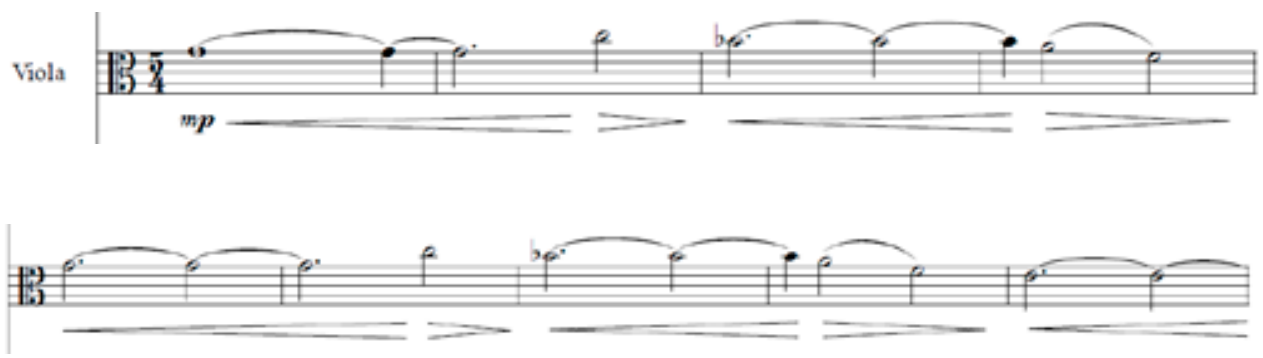

Figura 1. Tema principal presentado por la viola. cc. 1 al 10.

Trio clarinete, viola y piano (op. 001f) Liduino Pitombeira

En esta versión, el tema principal de la obra es presentado por la viola. Sin embargo, si escuchamos la canción popular en la cual se basa la obra, ${ }^{4}$ fácilmente se nota que el compositor presenta esta frase de una manera más ligera, ${ }^{5}$ aprovechando el color que provee el registro medio de la viola, acompañada por el piano. En el c. 13, el clarinete toma el tema acompañado por la viola en forma paralela, una tercera por debajo. El piano conduce la pieza con elementos del ritmo de baião que originalmente llevan el acordeón y el triángulo, pero de una manera más ligera y dentro de un lenguaje menos explícito de lo folclórico. Hacia el c. 28 con anacrusa, el clarinete inicia el estribillo, esta vez sí con un carácter muy folclórico, fiel a la canción original. Luego, hacia el c. 31, los tres instrumentos reexponen el tema principal juntos.

\footnotetext{
Ver el video de PEAO (2009).

5 También ver versión en video del op. 001c, donde el tema es asignado a la flauta o al violín (Benedetti, 2015).
} 


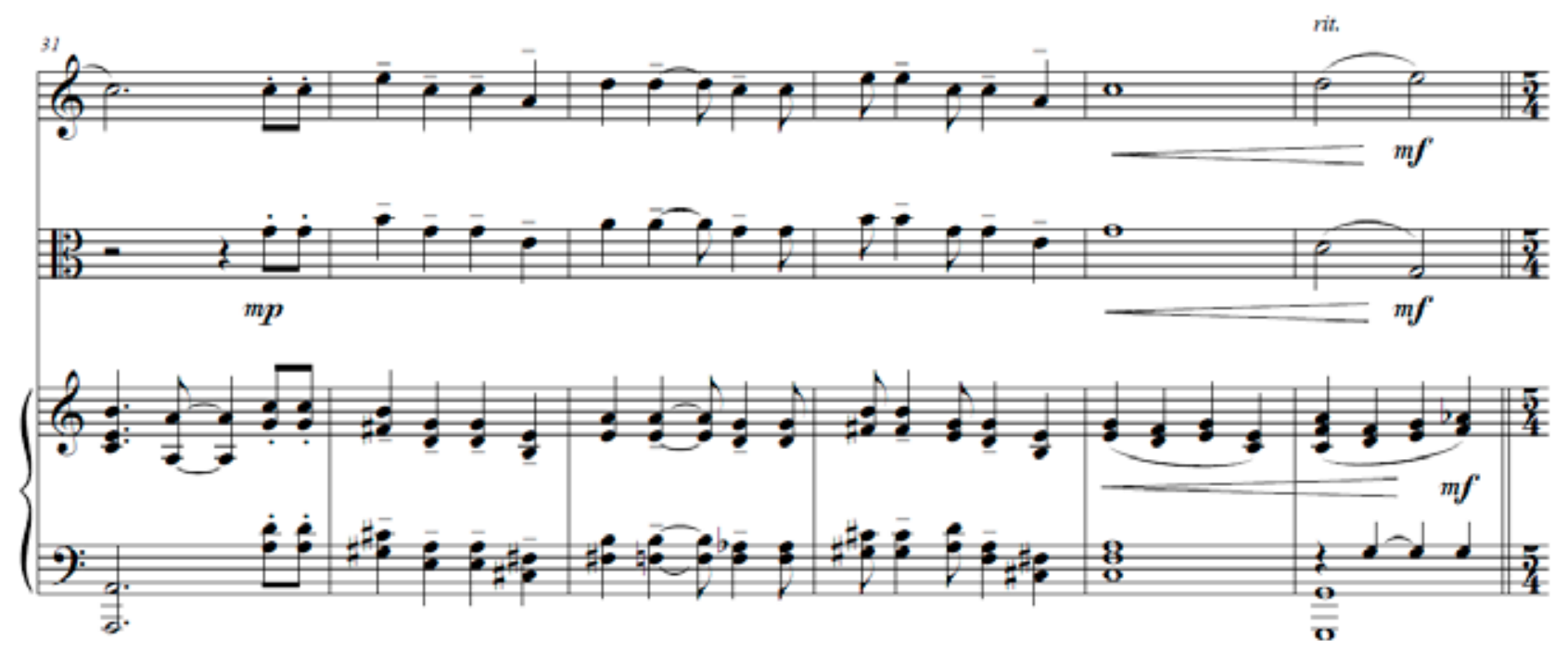

Figura 2. Coro de la canción original, escrita en esta sección para los tres instrumentos.

La forma de la pieza puede describirse así: A A' B A" B'. La obra comienza presentando el tema en el modo de Do mixolidio, que es el primer modo usado en la música nordestina (Siqueira, 1981). El tema principal de la obra, que corresponde al estribillo de la canción popular, es presentado por la viola (cc. 1-11); Luego, el clarinete presenta una escala de Sol menor (c. 11), que empieza a conducir la pieza hacia la reexposición de la melodía (c. 12) al unísono con la viola. En el c. 19, por medio de una secuencia de terceras, el clarinete conduce nuevamente el tema con la viola, a distancia de terceras, llegando al centro tonal de Fa (c. 23). Durante dicha secuencia, el piano duplica las notas de ambos instrumentos melódicos y les agrega una armonía cuartal. Siempre que se presenta la melodía, el piano la acompaña con el ritmo característico de baião (reducción de lo que originalmente es interpretado por el acordeón, el triángulo y el zabumba). La primera parte de la sección A (cc. 1-27) está escrita en la métrica de 5/4 y cuando aparece el estribillo de la canción popular, por primera vez, en el c. 28, la métrica cambia a la de 2/2, propia del baião.

Hacia el c. 37, el clarinete retoma el tema A, acompañado por la viola con notas repetidas con spiccato en intervalos de cuarta (Do-SoL). Luego, es la viola la que retoma el tema, y el clarinete, acompaño en contramelodía con un motivo repetido sobre modo Do mixolidio (SoL-FA-SoL-LA-SI ${ }^{\mathrm{b}}$ ), material que será retomado por la viola más adelante. El piano acompaña con el ritmo característico de la obra, repitiendo la fórmula armónica presentada anteriormente. Entre los cc. 59 a 65, encontramos un nuevo centro tonal sobre $A^{\text {b }}$ preparado por una secuencia de cuartas igual a la sucedida dentro de la sección.

Ahora bien, en el tema B de la obra, el material melódico usa pequeñas células musicales del estribillo original, mediante una llegada melódica por escala de tonos enteros en 
la viola y el clarinete con distancia de terceras mayores y movimiento de fabordón en el piano. Así mismo, se está cerca de un desarrollo de ideas mucho más cantábile y contrastantes con respecto al tema de la canción (espressivo), donde el piano acompaña las líneas melódicas de los instrumentos melódicos por medio de agregados (clusters). En los primeros once compases de esta sección (cc. 76-87), el clarinete propone una nueva melodía sobre el tercer modo real nordestino, llamado modo nacional brasilero ${ }^{6}$ (Siqueira, 1981), donde la viola lo acompaña.

Finalizando esta sección, se encuentra un solo de piano entre los cc. 100 y 107, mediante un juego melódico de arpegios sobre $\mathrm{Sr}^{\mathrm{bm}}-\mathrm{RE}^{\mathrm{m}}-\mathrm{Sol}$, como puente que conduce a la reexposición del tema A. Entre los cc. 108 y 130, se halla nuevamente con la sección A, donde se observa el mismo tratamiento melódico usado, con la diferencia de que, esta vez, el clarinete inicia la exposición del estribillo y luego es complementado por la viola y el piano, para continuar con el mismo material melódico de la sección B. Finaliza con una pequeña coda a cargo del clarinete, con acorde final con viola y piano sobre $\mathrm{Fa}^{7}$.

Los instrumentos no tienen que realizar un gran despliegue técnico, ya que la obra es bastante sencilla en cuanto a los elementos que intervienen para su interpretación. La melodía, emotiva y delicada, siempre es presentada legatto, como se ha expuesto anteriormente, entre clarinete y viola, salvo los lugres del estribillo, donde se encuentra un unísono general. El cuidado, es escucharse y saber conectar las frases, sobre todo, cuando el piano es el que dobla estas frases.

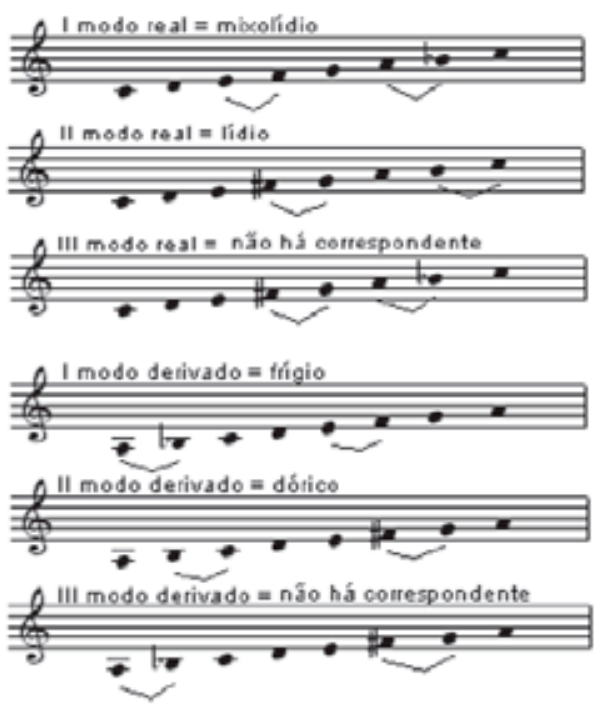

Figura 3. Modos nordestinos Fuente: Siqueira (1981).

6 Este modo nace de la clasificación realizada por José de Lima Siqueira, de los usos modales en la música folclórica nordestina (Siqueira, 1981). El modo nacional brasilero surge de una escala mayor, normalmente a partir de DO, con cuarto grado sostenido y séptimo bemol, y es denominado, por él, "III modo real". El modo mixolidio, en el cual comienza la obra, es denominado en esta clasificación como "I modo real". Esto se puede apreciar en la Figura 3. 


\subsection{Brasiliana op. 173c}

Compuesta originalmente para flauta, viola y piano y comisionada por el trío Brasilianas, integrado por Felícia Coelho (flauta), Aynara Silva (clarinete) y Maria Di Cavalcanti (piano), el 8 de junio de 20117 fue estrenada en el Conservatorio Pernambucano de Música. En 2016, Pitombeira realizó una nueva versión para clarinete, viola y piano, para A-Trío, integrado por Daniel Rosas (clarinete), Sarah Nascimento (viola) y Danieli Longo (piano). Existe también una segunda versión, denominada como $b$ para violín, clarinete y piano, adaptada por el mismo compositor. Está compuesta por tres movimientos, inspirados en tres textos de Machado de Assis $^{8}$ y ordenados de la siguiente manera.

\subsection{Flor anônima}

Flor anónima, de Machado de Assis, es la historia de una mujer de 45 años que acaba de separarse y va a vivir con una tía. Un día, recordando cartas que estaban guardadas, encuentra una flor entre ellas, dada por la única persona que amó en la vida, a quien había rechazado (Literatura Brasilera, 1994).

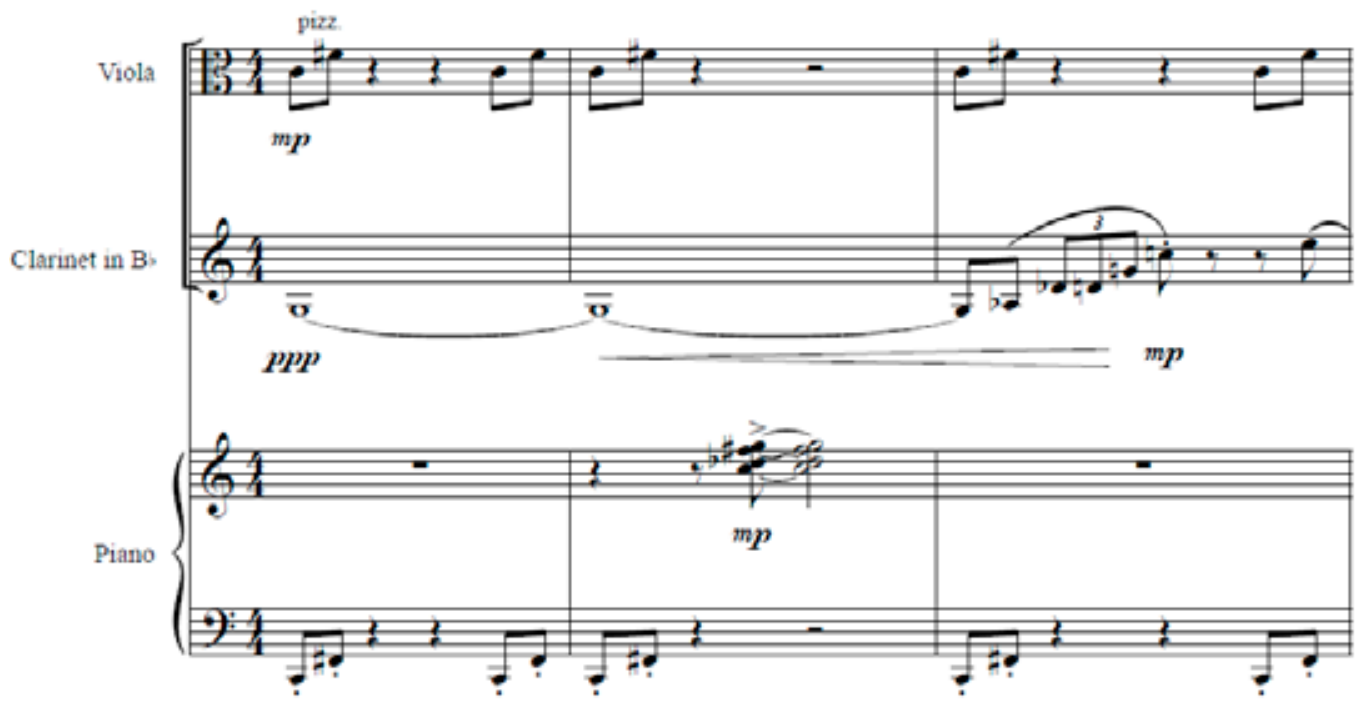

Figura 4. Motivo estructurador del primer movimiento, expuesto por la mano izquierda del piano y la viola.

Ver Trio Brasilianas (2018). Falta la referencia

8 Joaquim Maria Machado de Assis (Río de Janeiro, 1839-1908). Escritor brasileño ampliamente conocido por su incursión en diferentes géneros literarios: poesía, ensayo, cuento y novela. Documentó también el paso de Brasil de imperio a república, describiendo los sucesos político-sociales ocurridos en su época. 
La Figura 4 muestra el motivo estructurador del primer movimiento. El intervalo de cuarta aumentada (en Figura 4, que describe la introducción: Do-FA\#) es reiterativo y mantiene el hilo conductor de la pieza. Se encuentra, desde el primer compás, que el clarinete lleva una nota pedal hasta el tercer compás, donde finaliza una frase muy tensa que define el carácter de la pieza y que se mueve por cortas melodías en intervalos de cuartas, tanto ascendentes como descendentes, para la viola y el clarinete, fijando así la exposición temática de la pieza (cc. 1-4).

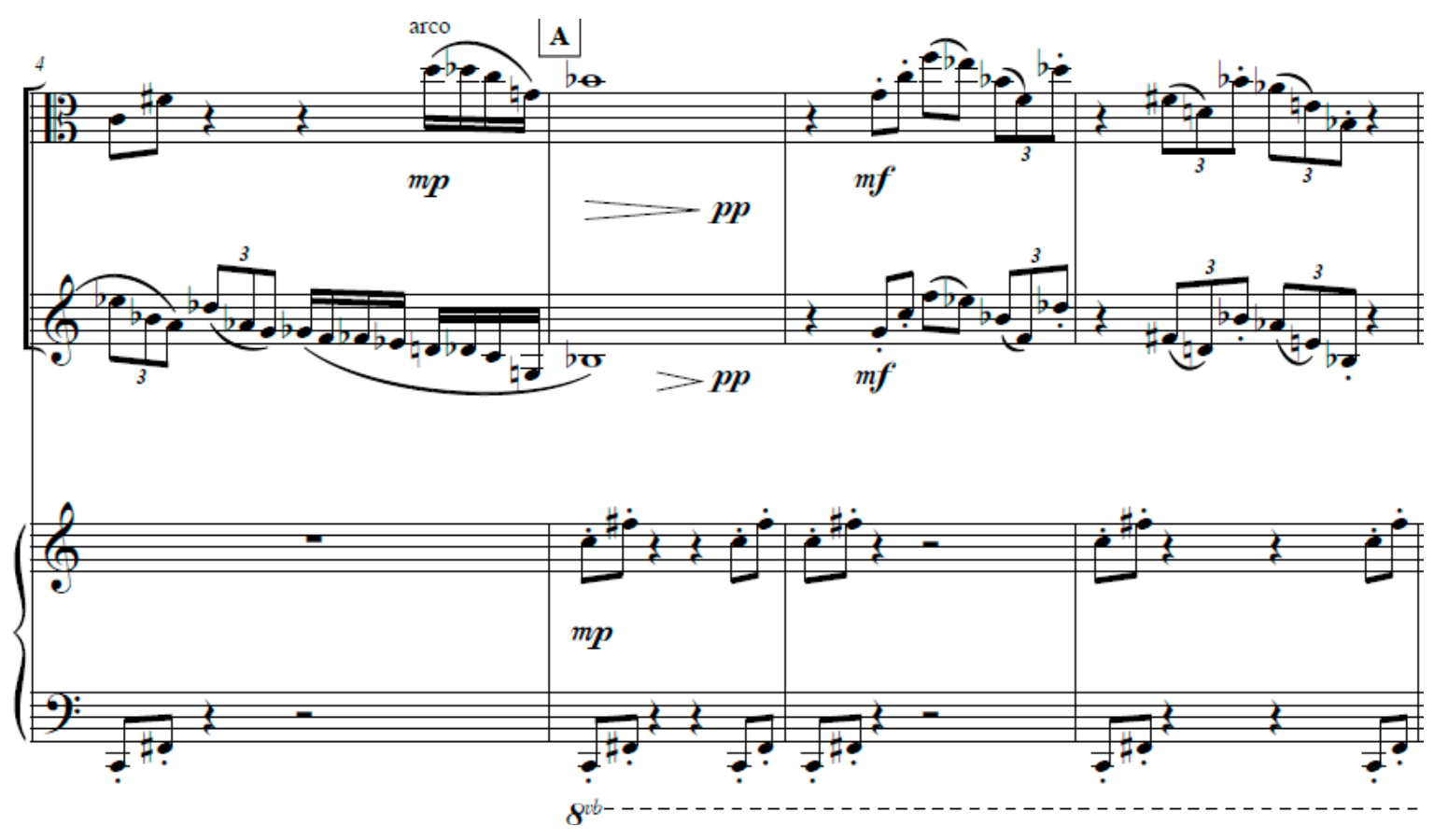

Figura 5. Letra A (a partir de c, 5). Motivo melódico reiterado por el piano y melodías por intervalos de cuartas, recurrente en viola y clarinete.

Mientras el clarinete y la viola se mueven por movimiento cromático en los cc. 2835 , el piano continúa la marcha de la pieza por medio de un ostinato con acordes de cuartas aumentadas, relacionados así: Do-FA\#, RE-SoL (cc. 27-25, superpuestos para la mano derecha, mientras el bajo ejecuta el motivo recurrente en corcheas con una anacrusa y reiteración consecutiva en intervalo de cuarta disminuida $\mathrm{MI}^{\mathrm{b}}$-LA. Se cierra la sección con un agregado que superpone intervalos de cuarta aumentada en el piano, que incrementan la tensión con los instrumentos melódicos, que tocan, a su vez, la cuarta aumentada Do-FA\#, articulados por un trino, cada uno.

Como punto de relajación, llegamos a la letra F, donde se puede observar el mismo ostinato inicial por parte del piano y movimientos melódicos cromáticos leves de la viola, con aumentación respecto a las ideas presentadas en la letra D, desplazando las negras un pulso y terminando la secuencia de cuartas, propuesta inicialmente, con saltos de 7m y 7M y 5J. Termina la sección con notas largas, inicialmente a distancia de cuarta justa y resuelve en un intervalo de sexta menor. 


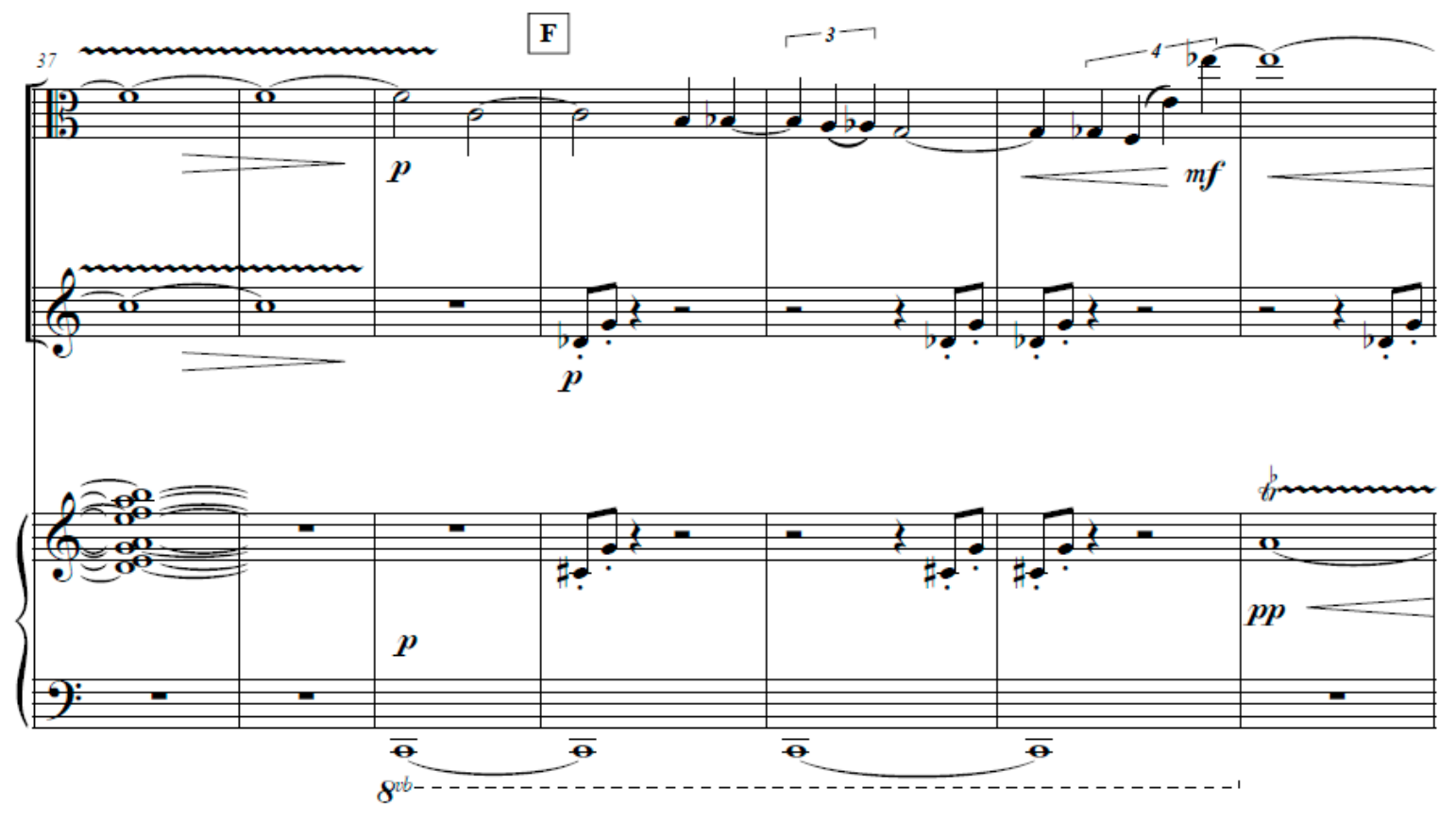

Figura 6. Letra F. Punto de estabilidad y transición

Continuamos con las letras $\mathrm{G} \mathrm{y} \mathrm{H}$, donde el piano es protagonista y ofrece un color distinto del que se venía trabajando, ya que las notas superiores proporcionan una melodía más suave y clara, luego reemplazada por acordes triádicos en un plano tonal (cc. 49-54); el bajo acompaña arpegiando estos acordes propuestos por la melodía. Melódicamente, la viola y el clarinete inician un juego de doble pregunta con su respuesta, mediante melodías que contienen una anacrusa cromática y continúan con saltos de terceras o cuartas. Para la letra I, regresamos a un insistente ostinato entre los tres instrumentos, con material melódico por cuartas aumentadas y justas, ya antes usadas en la letra $\mathrm{A}$. 


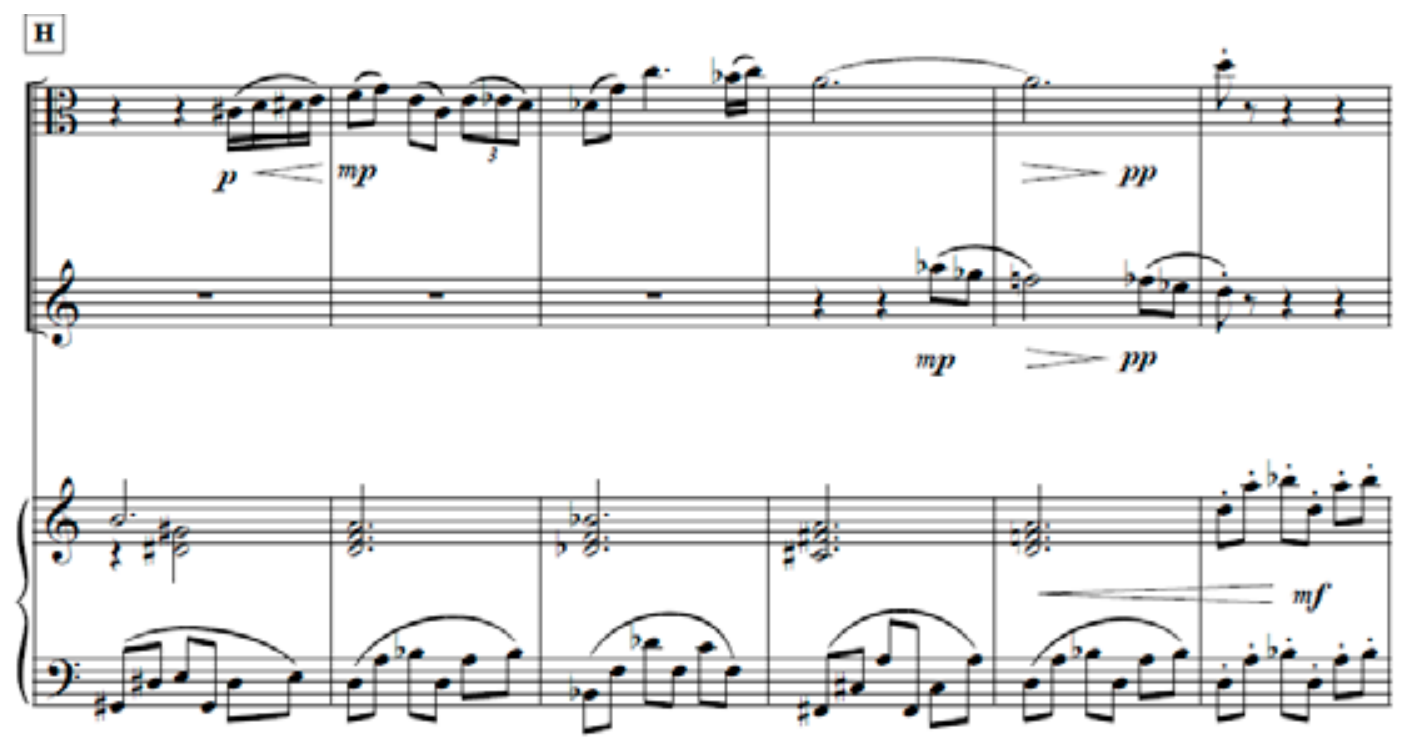

Figura 7. Letra H, cc. 49-54. Arpegios del piano y melodía de la viola y el clarinete.

Finaliza este movimiento con una sonoridad más calma sobre un acorde de Sol con 5. disminuida, formado entre los tres instrumentos. El clarinete nos conduce a un punto de reposo mediante cromatismos, partiendo de una armonía de $\mathrm{SI}^{\mathrm{b}}$ con quinta disminuida para llegar a un acorde de $\mathrm{LA}^{\mathrm{b}}$ mayor. Tras esta llegada, el piano realiza una serie melódica en contrapunto con materiales usados en anteriores secciones, finalizando al unísono en LA .

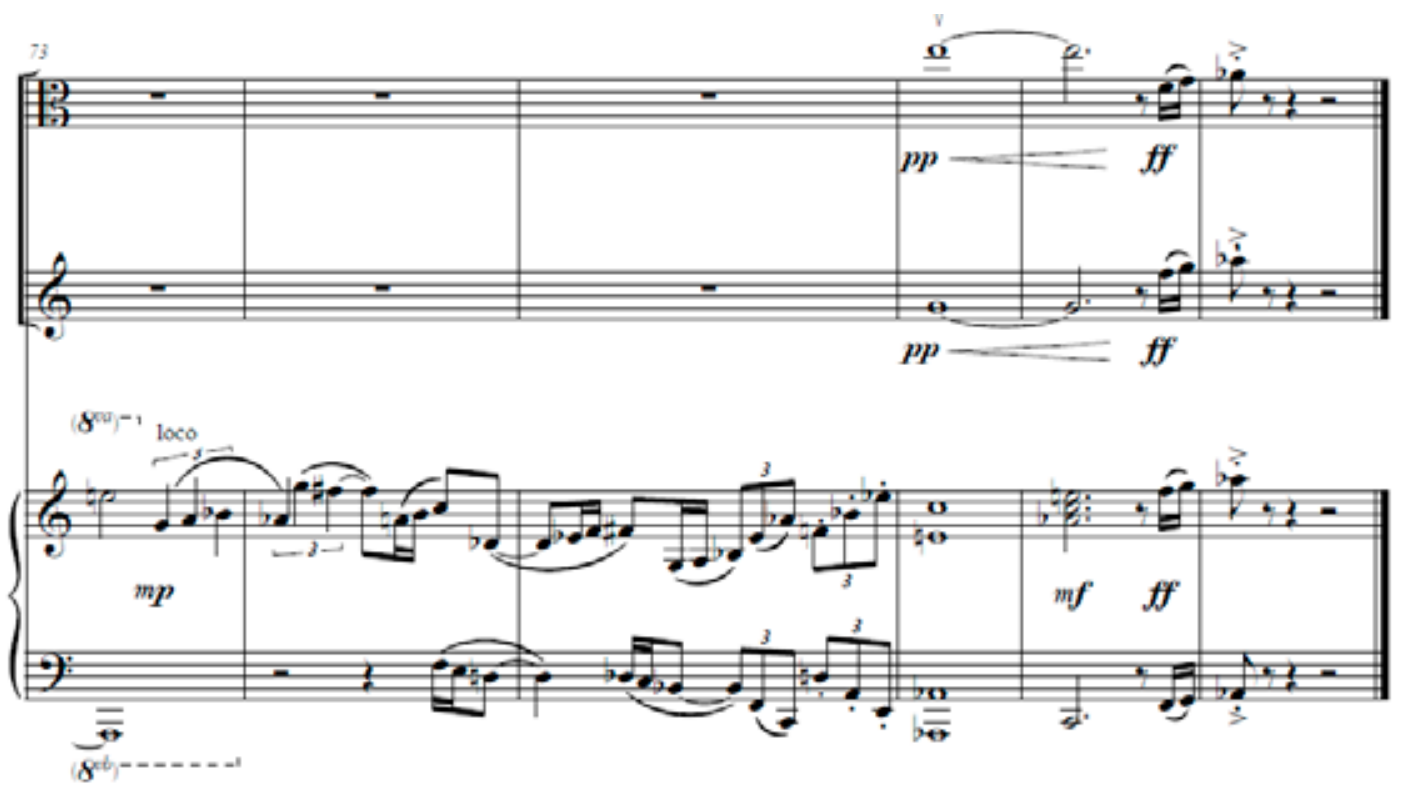

Figura 8. Final del movimiento (cc. 73-78). 
Encuentro, en relación con el texto, la tensión que genera, para la mujer, el recordar un amor pasado y pensar en todas las cosas que pudieron ser, pero que sus demonios internos no le permitieron vivir. El caos en el cual se sume ante su actual vida es representado por los cambios métricos y de ritmo propuestos, sobre todo, por los instrumentos melódicos. El momento de la resignación llega, finalmente, con la conducción rítmico-armónica hacia el LA ${ }^{\mathrm{b}}$.

\subsubsection{Ao acaso}

Este movimiento está basado en una crónica que data del 12 de junio de 1864, en la cual el escritor Machado de Assis (Literatura Digital, 2018) narra una serie de acontecimientos que se dan en la ciudad de Rio de Janeiro. Entre lo cotidiano, también va narrando situaciones de la política, de la sociedad y datos curiosos de quienes son expuestos en su narración.

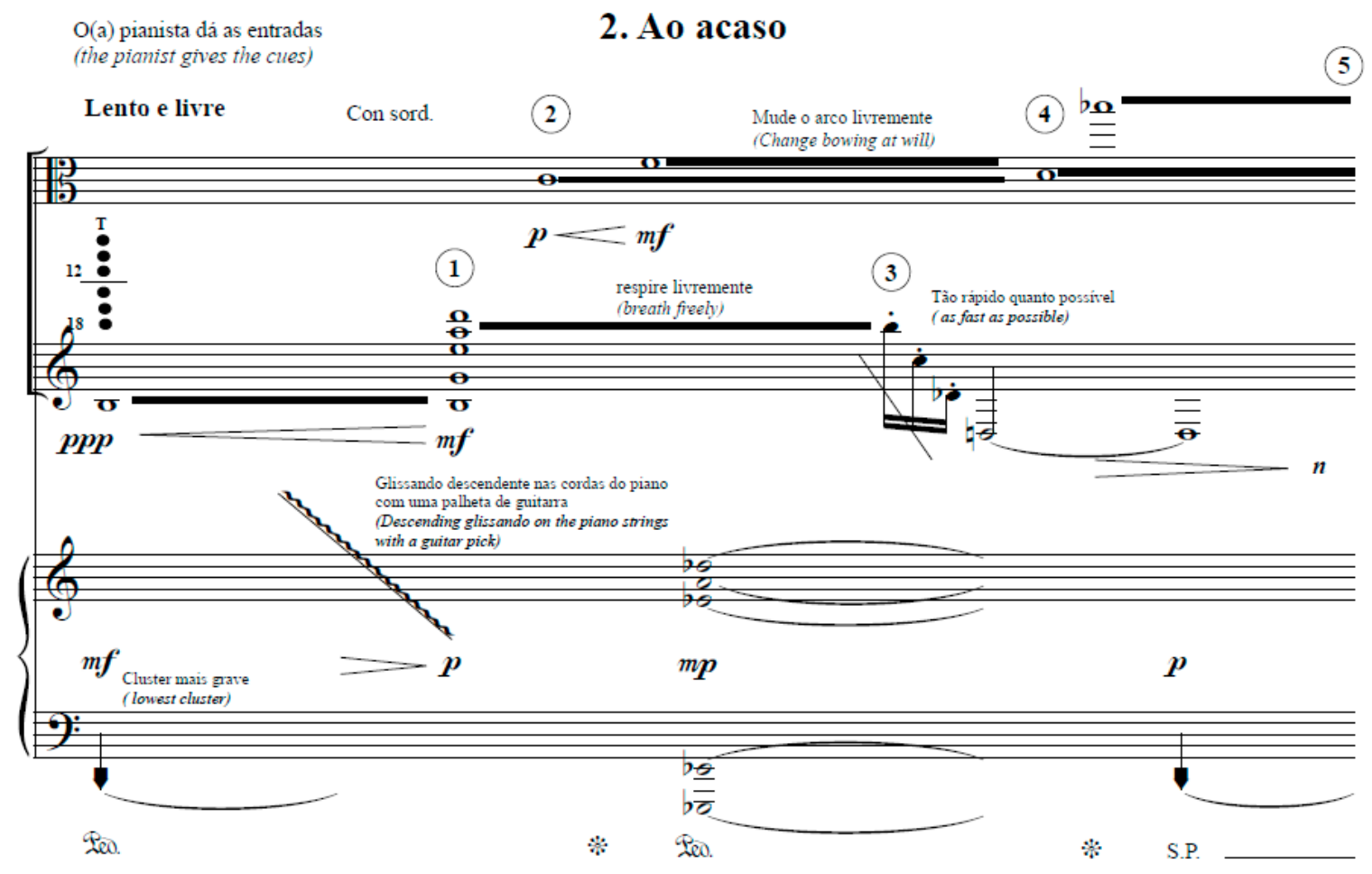

Figura 9. Comienzo del segundo movimiento.

A diferencia del lenguaje utilizado en el primer movimiento, esta parte se encuentra escrita con notación gráfica y la mensuración deberá ser indicada por el pianista. 
También emplea técnicas extendidas como las siguientes: el clarinete debe realizar una serie de multifónicos y adornos con saltos de séptima mayor que pasan por todo su registro posible, entre los números de ensayo del 1 al 3 y el 7. La viola debe realizar sonidos de duración determinados también por el piano, con distancias de cuarta, inicialmente en el número $2 \mathrm{y}$, en el 4 , con distancia de decimoquinta, siempre con sordina. El piano debe golpear con una plumilla las cuerdas del piano, manteniendo siempre un cluster muy grave y llenando también con acorde cuartal sobre $\mathrm{MI}^{\mathrm{b}}\left(\mathrm{MI}^{\mathrm{b}}-\mathrm{LA}-\mathrm{RE}^{\mathrm{b}}\right.$ ). En el número 5, el piano empieza una secuencia de "cajas" (ver Figura 5), donde se indica una serie de notas alteradas por intervalos de terceras mayores, inicialmente, y luego por cromatismo, con un descenso por cuartas justas y aumentadas (Do-Mi-Sol ${ }^{\#}-\mathrm{Si}_{-} \mathrm{Si}^{\mathrm{b}}-\mathrm{Sol}-\mathrm{La}-\mathrm{Fa}^{\#}-\mathrm{Do}^{\#}-\mathrm{Fa}-\mathrm{Re}-\mathrm{Mi}{ }^{\mathrm{b}}$ ). Esta serie de sonidos - con ligera variación de semitonos- se repetirá por la viola, una décima por debajo, y seguidamente el clarinete, dos octavas por debajo del registro de la viola. Termina el movimiento con una serie de notas en tremolo para el clarinete y la viola, con sonidos que van por distancias de séptima ascendente y cuartas descendentes, mientras el piano inicia una serie de glissandi que más tarde acogerán la viola y el clarinete.

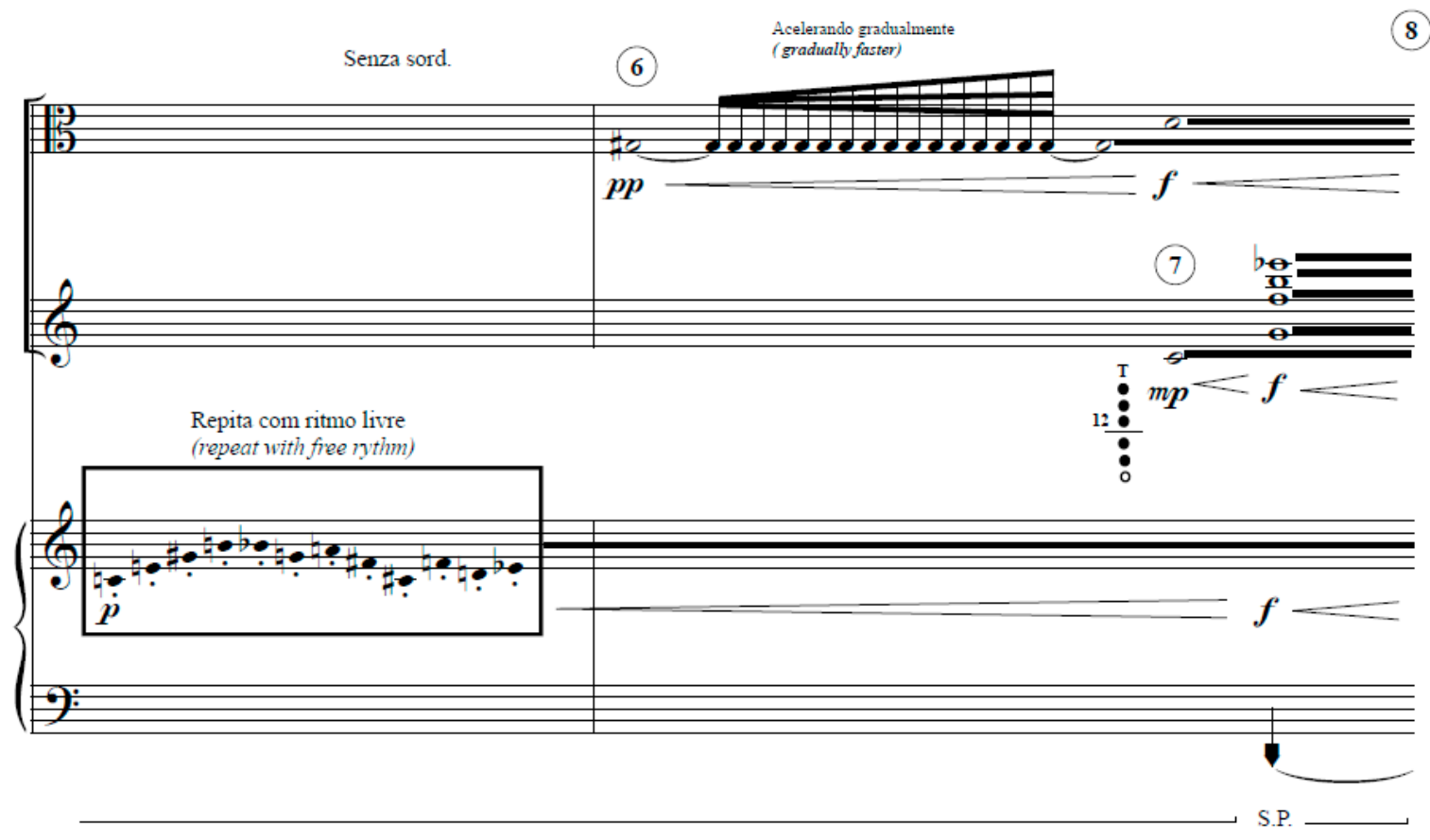

Figura 10. Número 5. Secuencia de cajas iniciada por el piano. Uso de multifónicos en el clarinete.

En cuanto a la relación texto-música, es posible que lasideas musicales expongan un caos social entre un orden preestablecido, pero dentro del cual giran las particularidades 
de cada individuo. Hay una pauta social que es seguida por otro individuo. También, está expresada la manera cómo el escritor narra las situaciones, puesto que, si bien describe una serie de situaciones, parece irse por las ramas, filosofando o encontrando respuestas a algunas situaciones que la misma sociedad propone.

\subsubsection{0 relogio de ouro}

La historia de Machado de Assis narra la situación de la extraña aparición de un reloj de oro en la casa de Luis Negreiros y su esposa Clarinha. La situación entre la pareja es tensa y se teje un gran malentendido por la respuesta de la mujer al no dar explicación alguna por la aparición del reloj y la desmesurada desconfianza del marido. Esta historia fue publicada en la gaceta Jornal das Familias en 1873 (Assis, 2018).

Para el entendimiento de este movimiento, se dividirá acá en cada uno de los aspectos relevantes por considerar: forma $\mathrm{A}$ B, donde $\mathrm{A}$ es una gran sección con elementos de células rítmicas y células melódicas tomadas de una escala pentáfona (SoL- SI- Do- RE- Mib). La sección B es más melódica y contrapuntística donde también el autor toma elementos usados en el primer movimiento.

\subsubsection{Melodía}

Las melodías están compuestas por series. La primera se encuentra entre los cuatro primeros compases y es desarrollada en los cc. 103 a 115, con los primeros 9 sonidos de la serie.

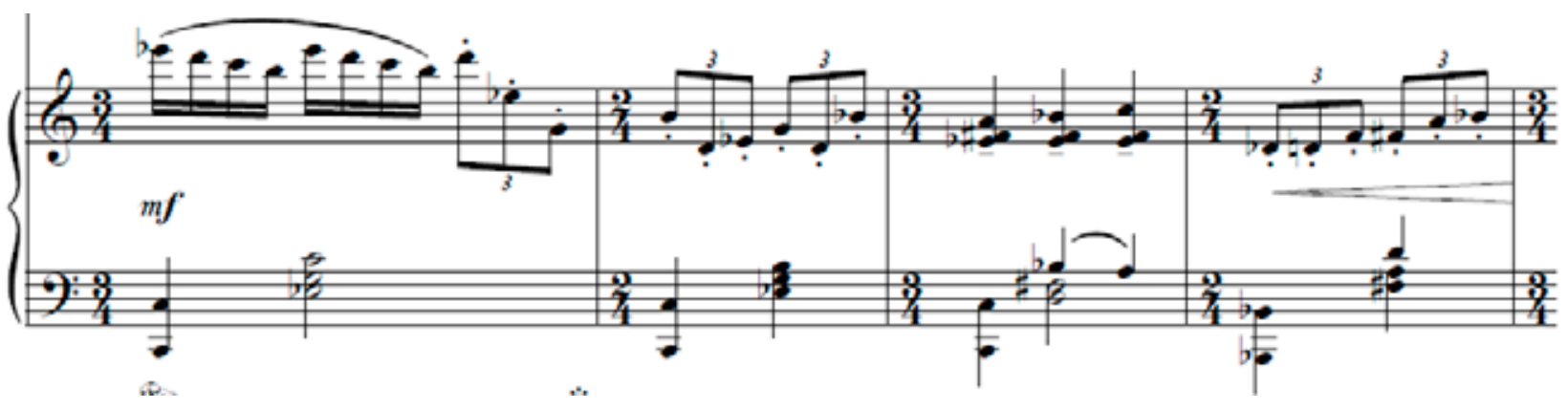

Figura 11. Primeros nueve sonidos de la serie melódica expuesta por el piano (cc. 103-106).

A partir de la letra B, utiliza los sonidos restantes de la serie (FA, MI, LA ${ }^{\mathrm{b})}$ en una frase 
al unísono entre los tres instrumentos, siempre guardando relaciones de intervalos de cuarta justa y segundas mayores.

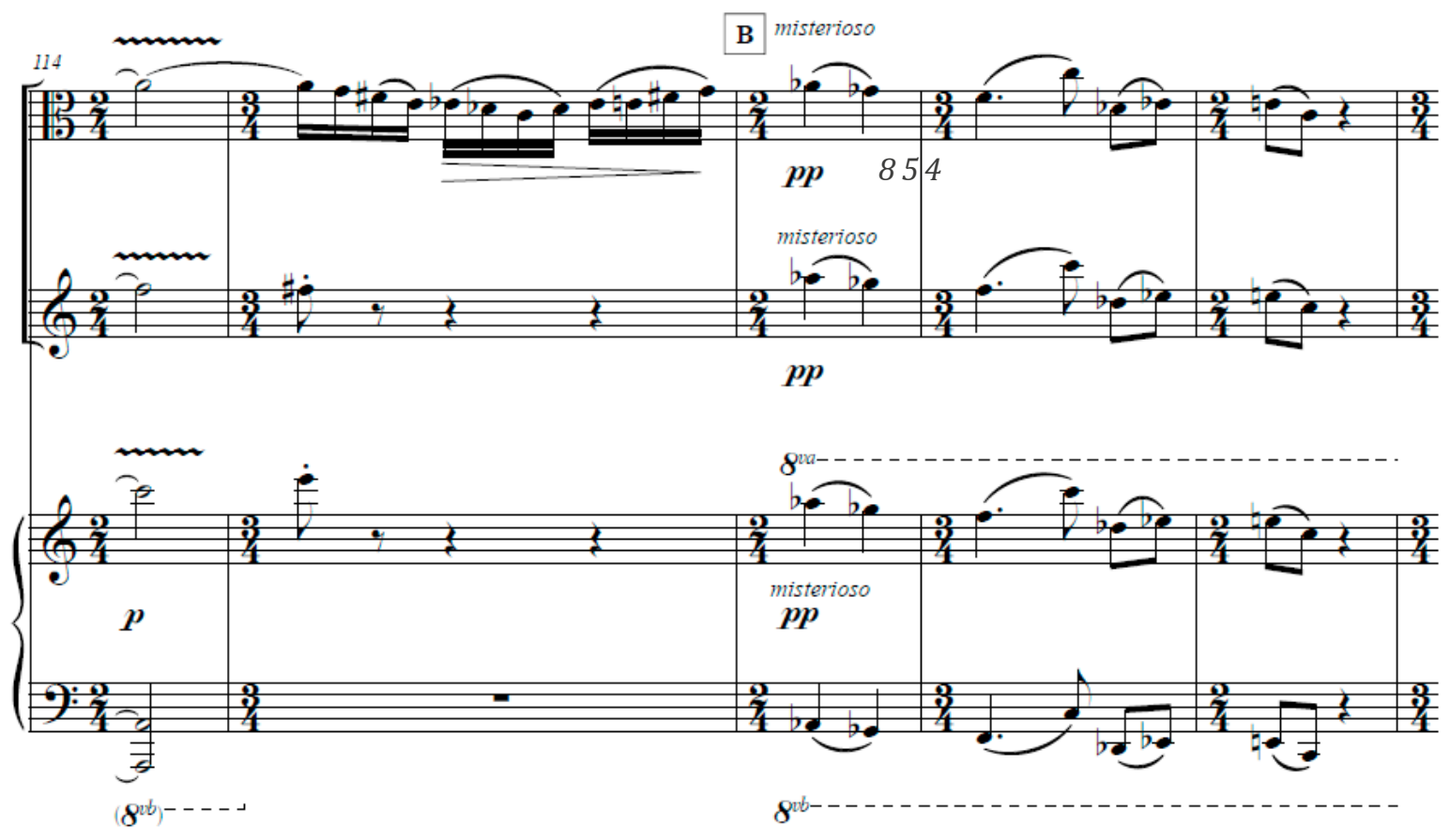

Figura 12. Letra B. Uso de los sonidos restantes de la serie

Las notas del primer compás serán usadas como ostinato recurrente en el piano en

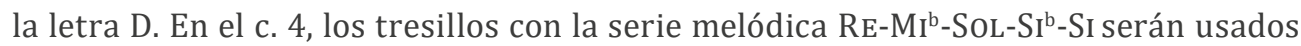
melódicamente por la viola y el clarinete en la letra F, logrando una simetría en cuanto la utilización de los materiales melódicos con el uso en tresillos tomado del segundo compás, ahora expuesto por la viola y literalmente por el clarinete. Esta melodía propuesta en tesillos, será usada más adelante como ostinato en el piano, con la egregación de notas en intervalos de sextas mayores y menores y cuartas justas, mientras la viola y el clarinete se mueven al unísono, con melodías más diatónicas y con algunos saltos de cuartas. 


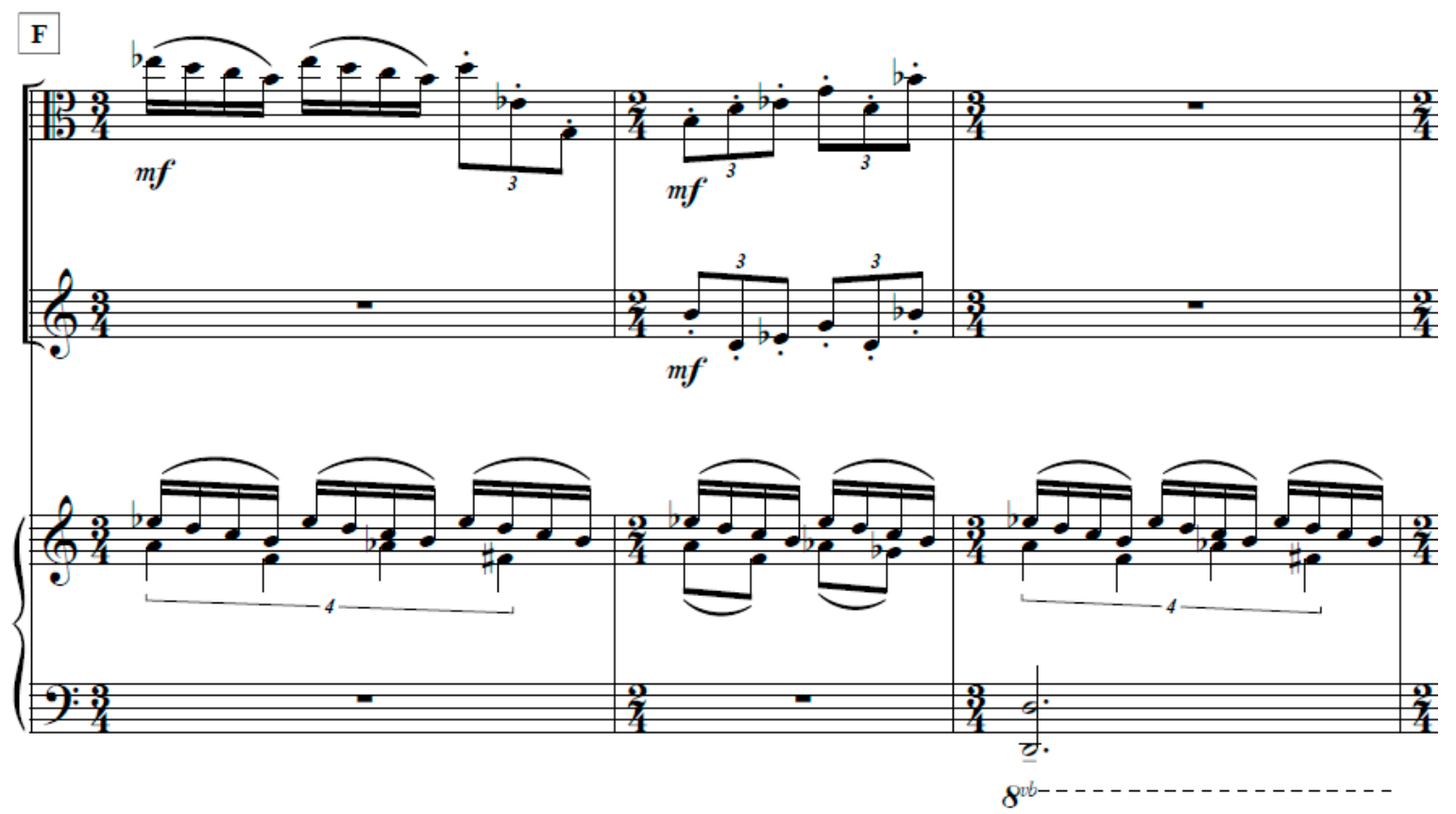

Figura 13. Materiales combinados y reexpuestos en letra F.

A continuación, se identifican los cuatro ostinato, en la mano derecha del piano, que determinan el carácter y ordenamiento de la pieza, con las caracteristicas descritas anteriormente en cuanto a la utilización de la serie propuesta.

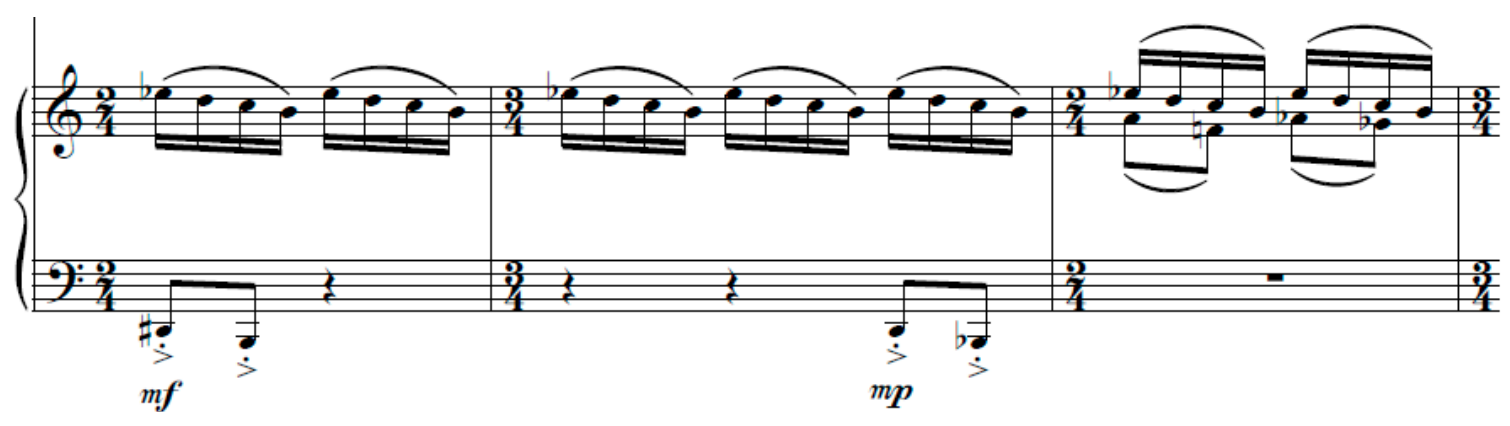

Figura 14. Primer ostinato primeros sonidos de la serie. cc. 128 a 130, letra E. 


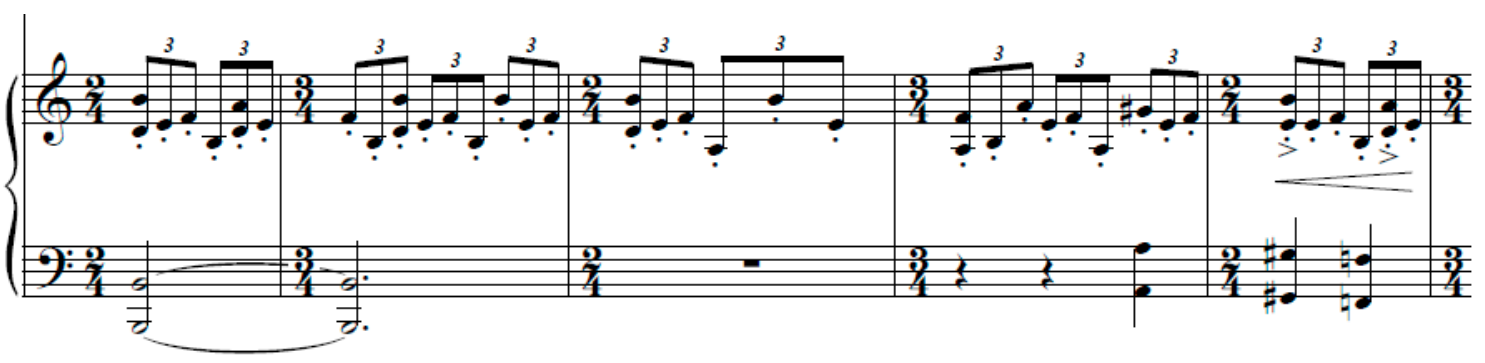

Figura 15. Segundo ostinato. Utilización de los sonidos restantes de la serie y agregaciones. cc. 142 a 146, letra $\mathrm{H}$.

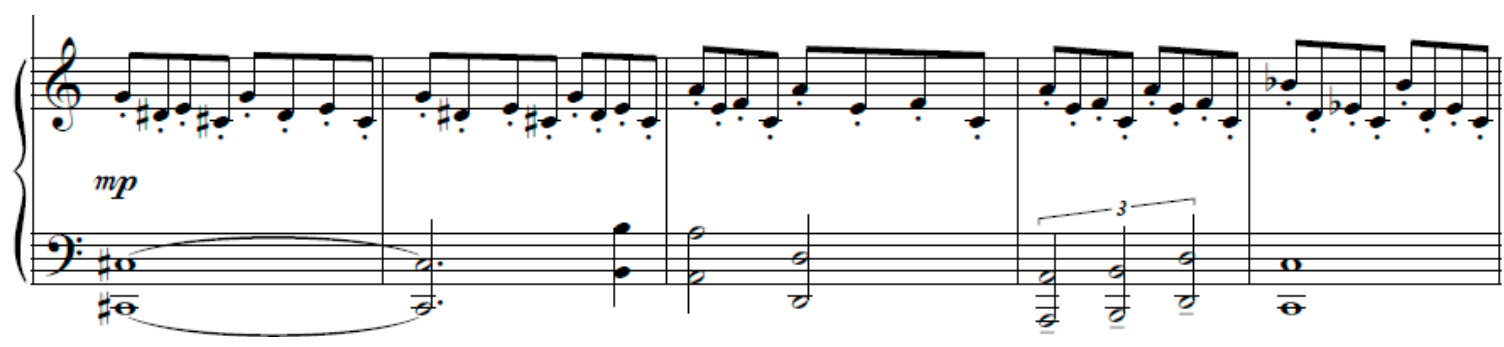

Figura 16. Tercer ostinato. Saltos de cuartas disminuidas y terceras mayores y menores. cc. 164 a 168, letra L.

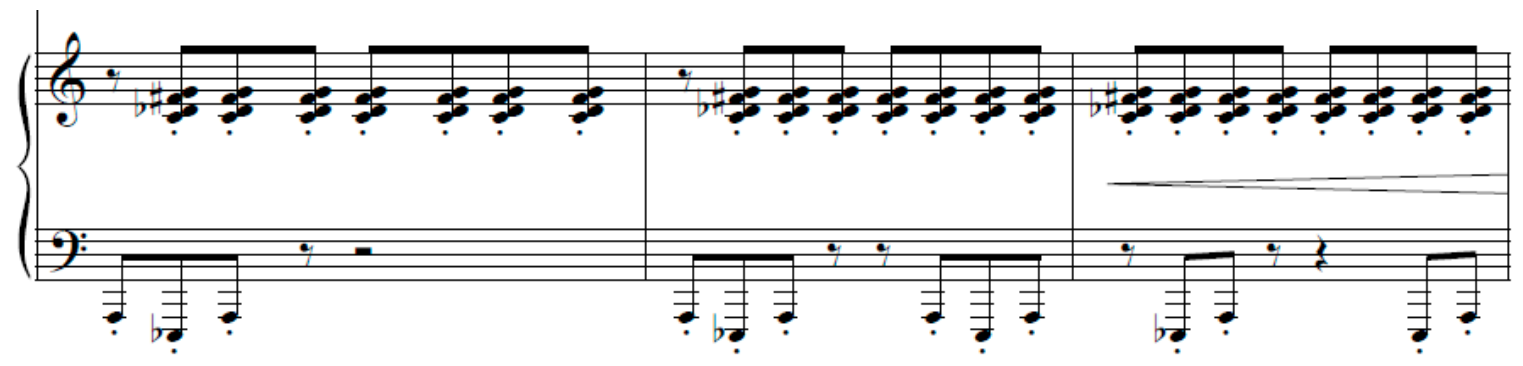

Figura 17. Cuarto ostinato del piano. Clusters en mano derecha con superposición de cuartas aumentadas. cc. 173 a 175, letra M.

\subsubsection{Textura}

Se aprecia una textura heterofónica de los tres instrumentos, en pasajes usados como puentes entre el desarrollo de ideas rítmico-melódicas. Por ejemplo, la letra B (cc. 116-120) y comienzo de la letra D (cc. 125 y 126). Sin embargo, en toda la sección que comienza en la letra D hasta la H, y cuatro compases antes de la letra J y hasta la $\mathrm{K}$, la viola y el clarinete ejecutan una melodía al unísono contrastando a manera de dúo con el piano, que realiza un ostinato rítmico sobre los grupos escalares descritos anteriormente, dispuestos en diverso orden. 


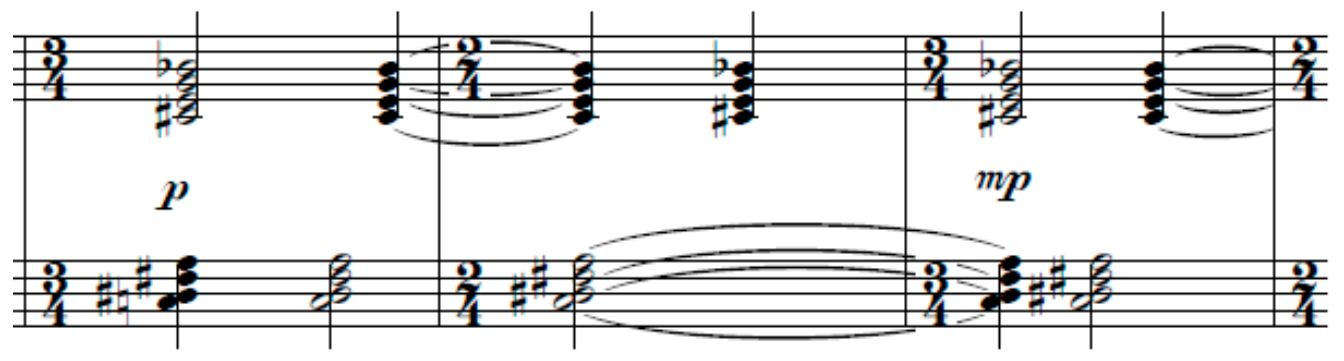

Figura 18. Letra C (cc. 121- 123). Armonía resultante en el piano, sobre la serie propuesta.

\subsubsection{Armonía}

La armonía es obtenida por la superposición cordal de las series de notas propuestas en cada sección, como en la $\mathrm{A}$, a manera de agregados o clusters que acompañan el contrapunto de viola y clarinete en unísono, contra el bajo que realiza la mano izquierda del piano, con la mano derecha que ejecuta tresillos que cumplen la doble función de ostinato rítmico y complemento armónico.

La relación vista entre texto y música es la analogía entre el reloj encontrado, según describe el texto, con la utilización de series con el uso de pitch class para crear relaciones en el uso de intervalos y enarmónicos en la construcción de motivos estructuradores y simétricos en las melodías y ostinati que desarrollan los instrumentos melódicos y el piano. También, en cuanto al discurso sonoro, resulta relevante que el ostinato del piano enfatiza la terca situación de celos del esposo y el silencio de la señora Clarinha, para poder dar solución al conflicto que los embarga. Finalmente, las melodías al unísono son interpretadas como la conversación de la pareja, en torno al querer saber de la procedencia del reloj encontrado. El cluster final resuelve la situación en la que la mujer rompe su silencio y se encuentran con la respuesta más inesperada, que da fin a la angustiosa situación.

En cuanto a la ejecución de la obra, como ya se ha mencionado, cada movimiento propone una serie de ideas independientes, encontrando interesantes los elementos y su utilización, propuesta por el compositor. Los intérpretes del clarinete y la viola deben lograr una mezcla de sonidos y resonancias cuando son propuestas las frases al unísono. El piano pauta siempre los puntos de encuentro y divergencia del discurso musical. Técnicamente, el reto se encuentra en la versatilidad del pianista al realizar algunos movimientos sobre el piano fuera del teclado y buscar la concordancia con los demás instrumentistas e indicar bien las pausas y entradas (segundo movimiento): el clarinete debe hacer uso de multifónicos, siendo el reto técnico más extremo en esta obra. Las demás melodías no exigen un despliegue técnico mayor o fuera de lo usual. 


\subsection{Paineiras op. 200}

Esta obra fue escrita para el trío Paineiras, integrado por Marina Spoladore (piano), Batista Junior (clarinetes) y Marco Catto (violín y viola) (Pitombeira, 2017), quienes comisionaron esta obra al compositor Pitombeira con la particularidad de ejecución de todos los instrumentos que ellos utilizan. Así es como esta obra está escrita para violín en su segundo y tercer movimiento, y para clarinete bajo en $\mathrm{SI}^{\mathrm{b}}$ en el primero (Praineiras, 2017). De esta manera se logra una mezcla de colores oscuros en el primer movimiento y colores más brillantes en el segundo y tercero. Los títulos de los movimientos son extraídos del poema "A Paineira e o Poente" de J. G. de Jorge Araújo. ${ }^{9}$

\subsubsection{Lembrança em turbilhão}

Movimiento escrito en forma A B A. Diseñado con textura mixta, ya que bien puede ser tanto homofónica como heterofónica, dada la alternancia de motivos al unísono en diferentes registros, así como por pequeñas secciones de contrapunto entre alguno de los instrumentos melódicos y el piano y el uso recurrente de melodía con acompañamiento.

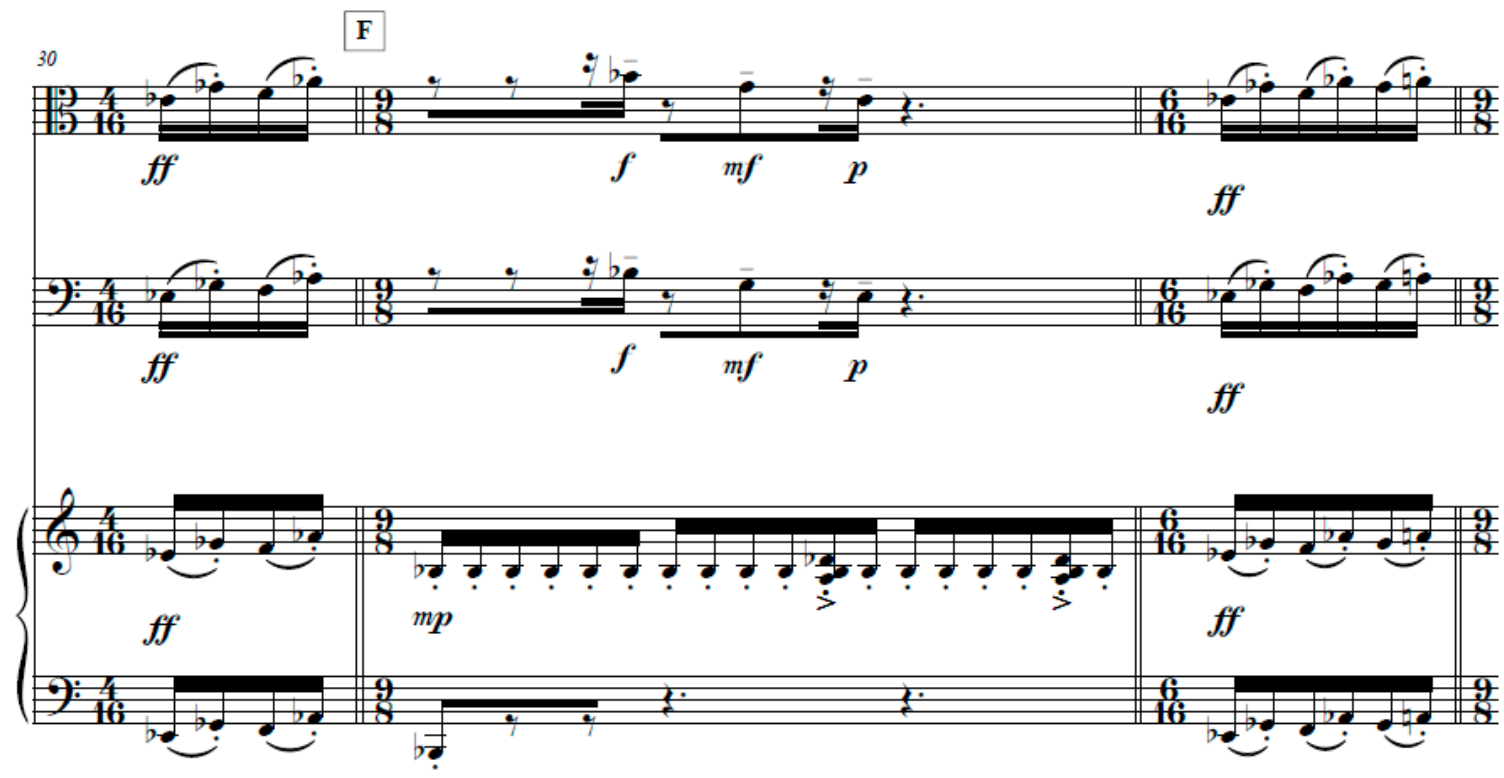

Figura 19. Melodías al unísono y alternancia con melodía y acompañamiento (ostinato)

9 Josè Gilherme de Araujo Jorge (Taraucà, Esado do Acre, 1914; Rio de Janeiro, 1987). Poeta y político brasileño, conocido por ser orador de entidades universitarias. Ejerció cargos públicos en Brasil. Fue conocido como El poeta del pueblo y de las juventudes. 
Respecto a las anteriores obras analizadas, se descubre la recurrencia del autor en el uso de unísonos para los instrumentos melódicos y acompañamiento por medio de ostinato en el piano, que generan tensión en algunos puntos, con grupos de notas que funcionan como un eje articulador.

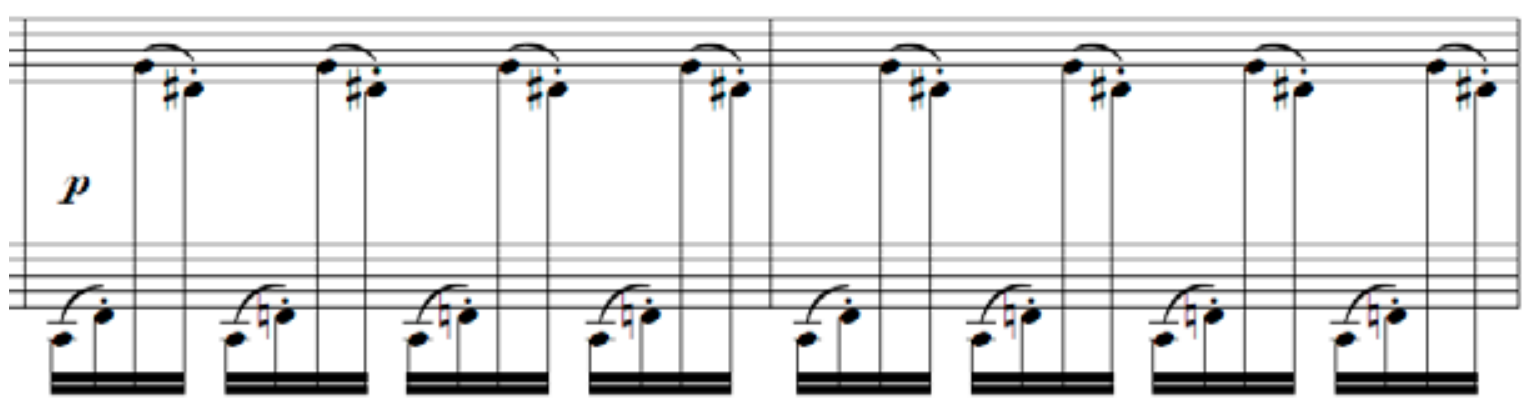

Figura 20. Ostinato presentado por el piano en cc. 8 y 9.

El ostinato que se aprecia en la figura 20, es usado inicialmente en el c. 8 y luego repetido en la letra Q. El diseño de este ostinato es repetido en el c. 16 y en la letra P, cambiando las notas iniciales, pero conservando la misma relación interválica de cuartas. En la letra $\mathrm{S}$, se puede observar que las notas usadas en el ostinato del c. 8 (C-F-B-F $/ \mathrm{G}^{\#}$ - $\mathrm{C}^{\#}$ $\mathrm{D}-\mathrm{G} / \mathrm{E}^{\mathrm{b}}-\mathrm{B}^{\mathrm{b}} \mathrm{E}-\mathrm{A}$ ) son utilizadas como material melódico para el clarinete y la viola a manera de pregunta y respuesta y, luego, al unísono, para concluir el movimiento.

Llama la atención el uso de métricas irregulares cambiantes y agrupaciones métricas. La tensión métrica comienza en la letra D (c. 19) en compás de 7/4, acrecentada luego por un compás de $3 / 4+3 / 8$, e inicia una alternancia entre compases simples y compuestos. Sin embargo, los compases simples presentados son los que contienen figuraciones largas y/o de reposo, causando (en relación con el título de la obra) un torbellino de sonoridades.

\subsubsection{Saudades ao redor}

La instrumentación de este segundo y luego, tercer movimiento, es violín, clarinete en $\mathrm{SI}^{\mathrm{b}}$ y piano. Su forma es bastante particular, dado que el material musical presentado desde el c. 98 hasta el c. 110, que completa 13 compases, será presentados después en retrogrado, desde el último compás (c. 127) hasta el c. 114. 


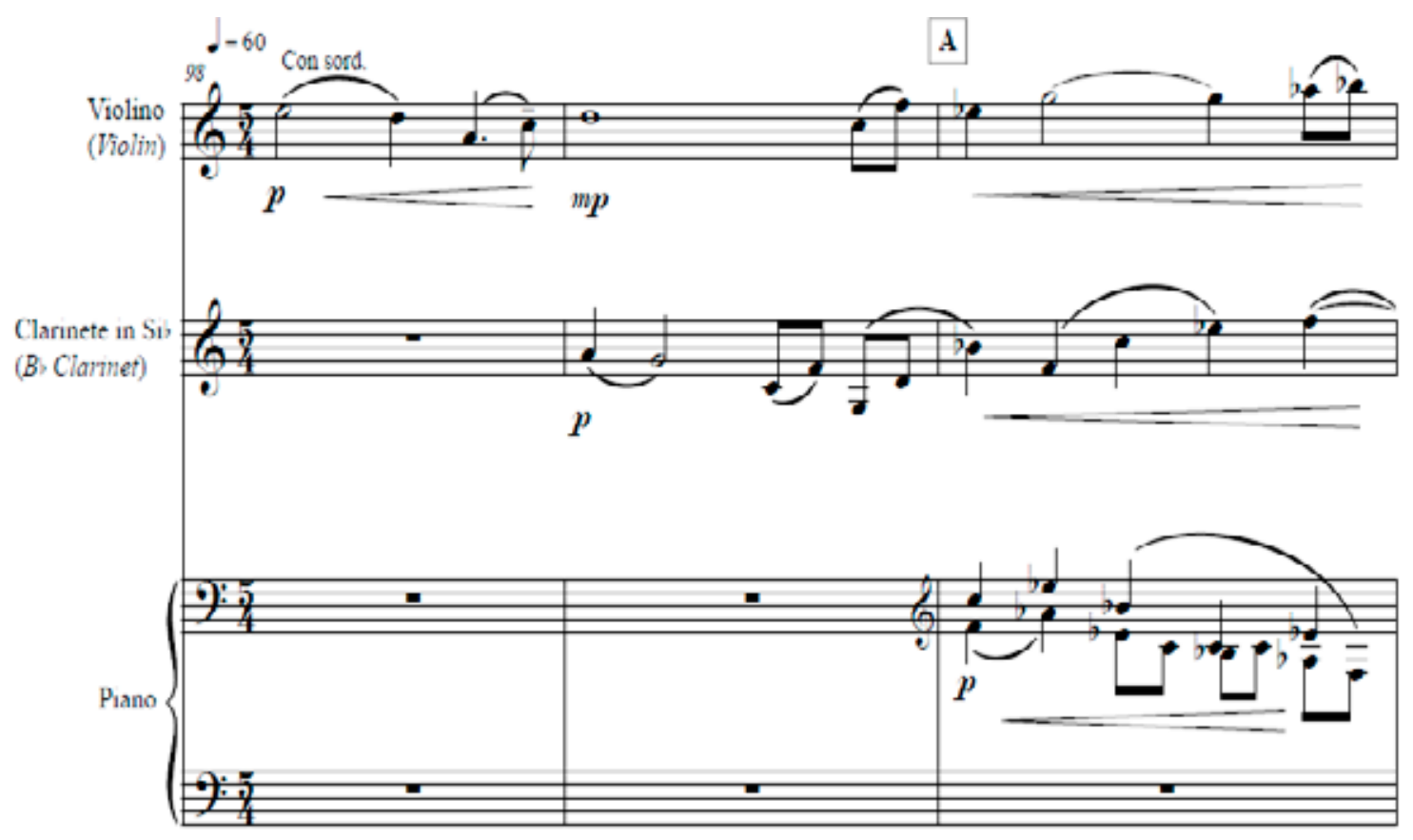

Figura 21. Comienzo del movimiento. cc. 98 al 100.

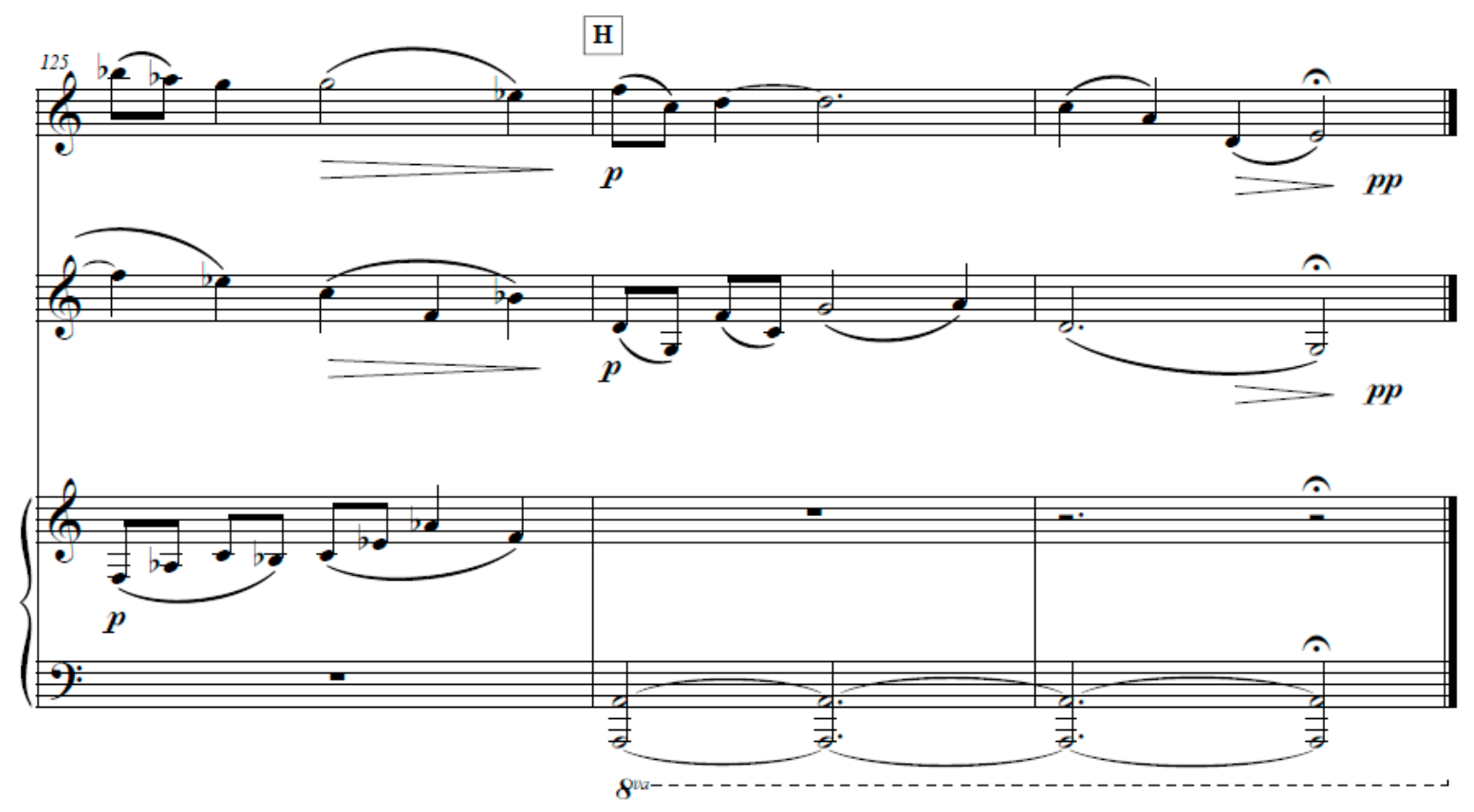

Figura 22. Final del movimiento. cc. 123 al 125.

Nótese en las figuras 21 y 22 que, a pesar del cambio métrico y las notas largas para la finalización del movimiento para el clarinete y el piano, el material melódico es 
similar en los tres instrumentos, cambiando registros una octava por debajo en cada instrumento. Se tomará como puente, transición e, incluso, disolución de lo anterior, el conjunto de compases del 111 al 114, regido muy notablemente por la armonía cuártica y con un detalle nuevo, el tremolo sul ponticello del violín. El pasaje siguiente comienza con el cancrisante (retrogrado) del clarinete con respecto al tema que tocó justo antes del puente (c. 110), procedimiento que luego toman los otros dos instrumentos.

\subsubsection{Dispersos}

Escrita en compás binario de división ternaria, 6/8, usando como textura la heterofónica, donde las voces son dispersadas al unísono, en distintos registros

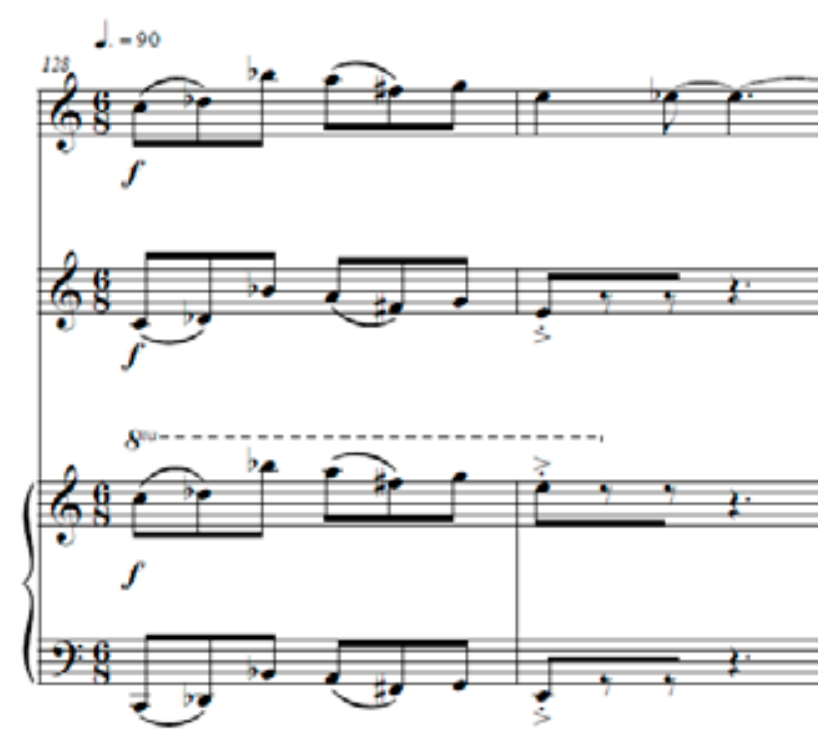

Figura 23. Comienzo del tercer movimiento. cc. 128 y 129.

La textura heterofónica continúa en la letra E por cinco compases; sin embargo, emplea los mismos sonidos en los tres instrumentos, aunque no necesariamente con ritmo igual, puesto que mientras clarinete y violín son isorítmicos, el piano varía en la mano izquierda, con la formación de acordes con ritmo contrastante (ver Figuras 24 y 25). Se halla heterofónia también en el compás 165 entre el violín y el piano. 

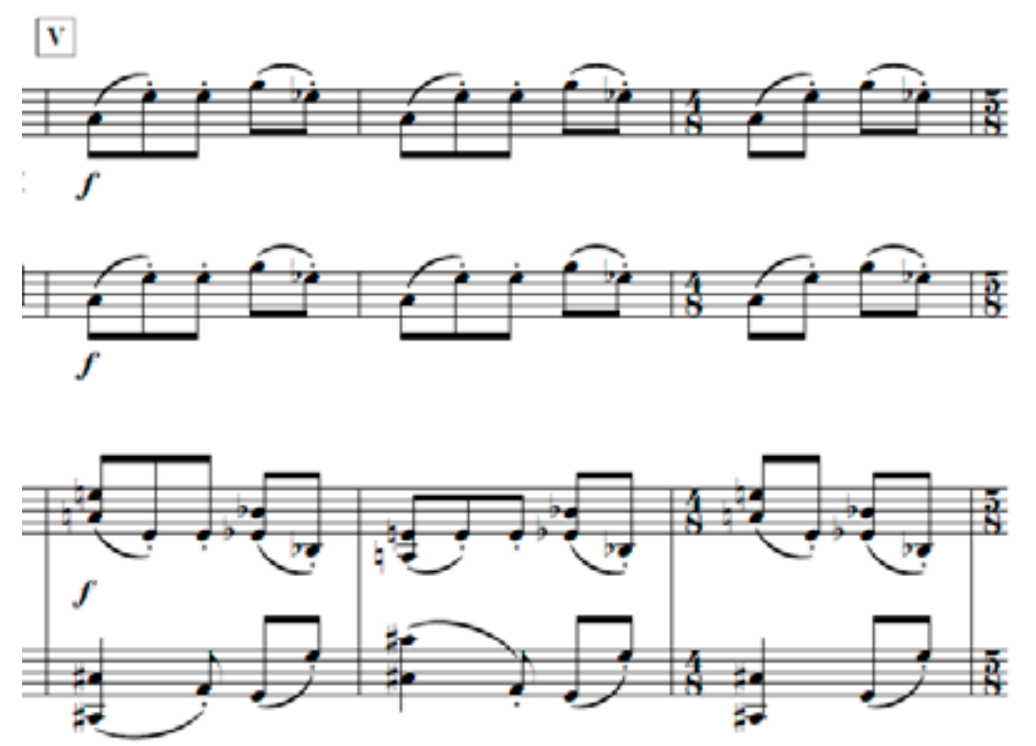

Figura 24. cc. 228 a 230. Serie de compases que se repiten (letra V), tomados de letra $\mathrm{E}$.
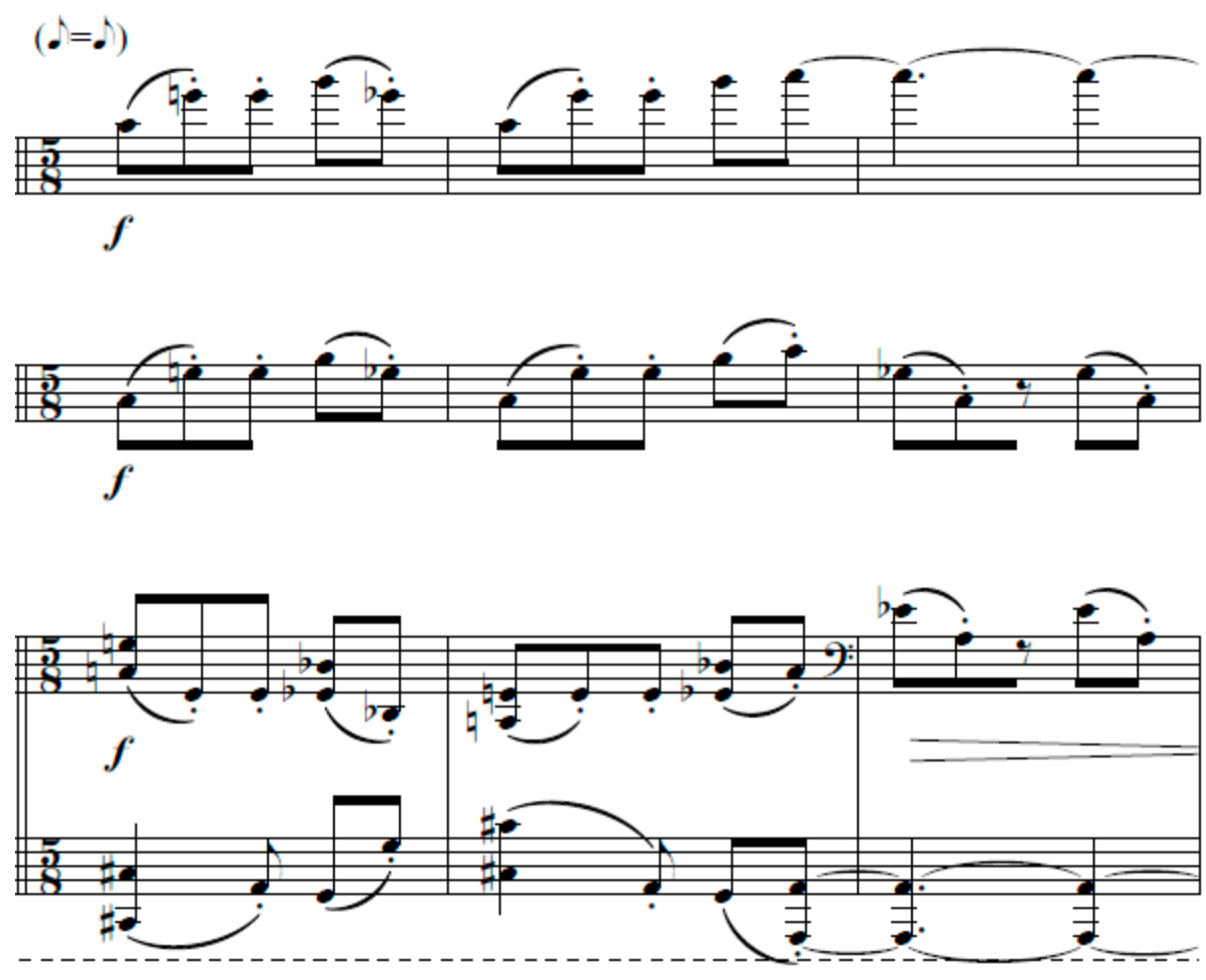

Figura 25. Letra E. cc. 155 a 157, para comparación con Figura 24. 
Finalmente, en la letra $V$, se encuentran los mismos elementos usados en la letra D, con repetición, por cuatro veces, de la serie de tres compases, pero una octava por debajo en el caso de violín y del clarinete, hasta la letra X.

La textura secundaria que se percibe en este movimiento es de melodía con acompañamiento. Se pueden apreciar pasajes como el que comienza a partir de la letra A, donde violín y clarinete realizan una melodía paralelamente en distancia de quintas justas (armonía cuártica otra vez), mientras el piano ejecuta notas largas en la mano izquierda, contrastando con un ostinato en corcheas, formando quintas justas en la primera corchea de cada compás. Se forma entonces en el piano una armonía por quintas, aunque variando con agregaciones, como sucede entre el c. 143, letra J, y la letra K. En la letra N, están el violín y el clarinete, en distancia de terceras, y realizan una melodía con el acompañamiento del piano, donde se generan armonía cuartal y arpegios en espejo entre manos derecha e izquierda (cc. 199 y 200). En algunos momentos, el clarinete varía la melodía que ejecuta heterofónicamente con el violín, realizando saltos de terceras o cuartas melódicas hasta encontrarse de nuevo con el canto del violín (letra P). En la letra Q, se encuentran frases de pregunta y respuesta entre el violín y el clarinete, para lo cual, el piano duplica lo que cada uno de los instrumentos melódicos ejecuta.

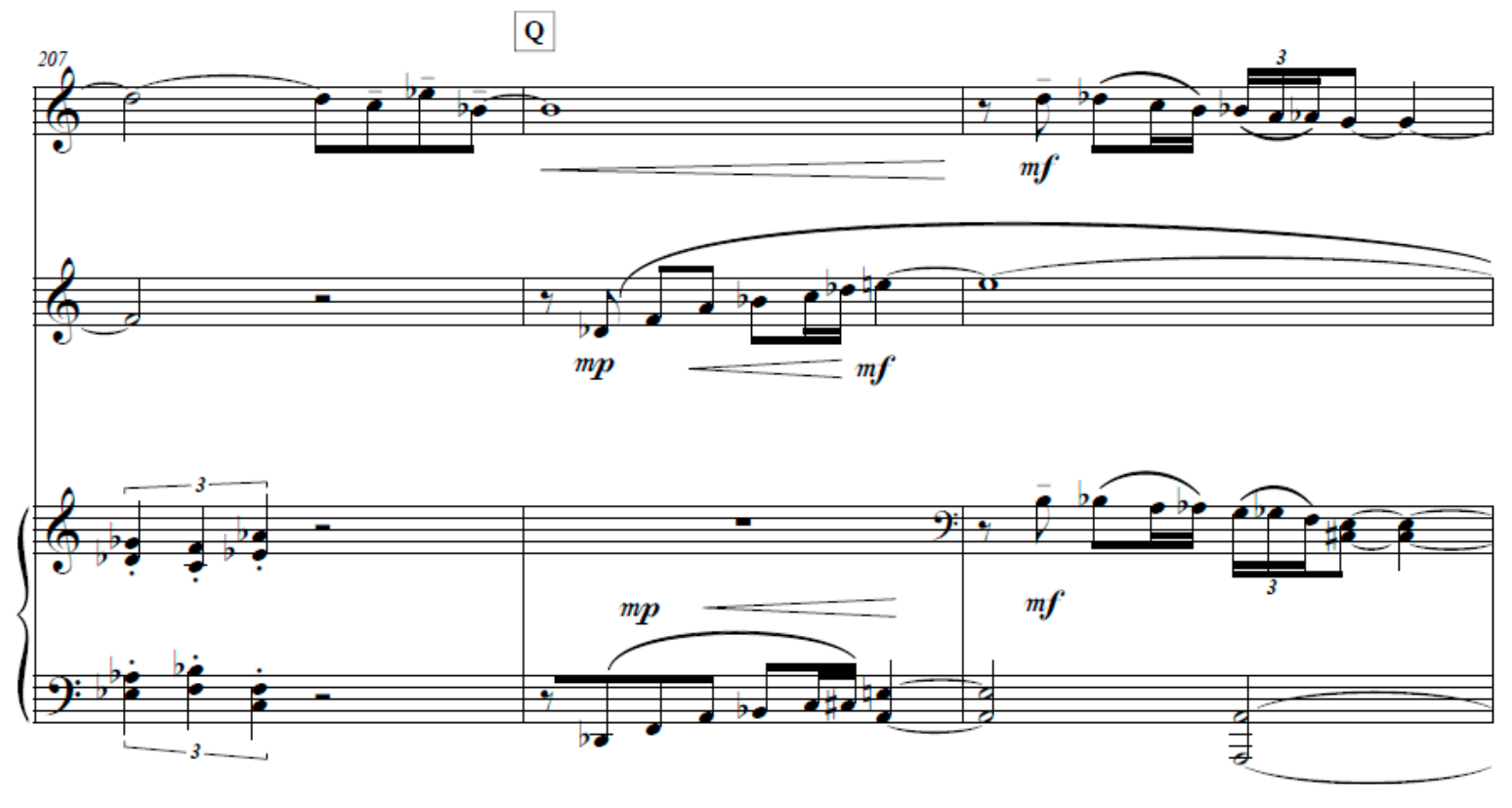

Figura 26. Duplicación del piano sobre las frases de pregunta y respuesta de violín y clarinete.

Finaliza en la letra Y, con el mismo material melódico y armónico usado en los cuatro últimos compases del segundo movimiento, con una variación del registro, una octava abajo, para clarinete y violín. 


\section{Conclusiones}

El caso del conjunto de clarinete, viola y piano es interesante por la mezcla sonora que logra. Sin embargo, es enfático en el uso del registro medio-bajo de la viola, en pasajes más poéticos, oscuros o líricos, mientras el clarinete es usado como un gestor de movimiento, de colores más brillantes y de gran exigencia tímbrica en cuanto al paso rápido de registros. El piano siempre ancla de alguna manera los instrumentos melódicos, sin dejar sus cualidades sonoras y permitiendo explotar sus registros extremos.

La composición del maestro Liduino Pitombeira propone una estética muy versátil, por la combinación de técnicas de composición que intervienen en cada parte de las tres obras, especialmente en las dos últimas. Es especial el manejo que hace de la sonoridad de los distintos instrumentos, puesto que no pierden sus timbres característicos y, a pesar del recurrente uso de unísonos, nunca se convierte en música pesante o aburrida. Logra una mezcla interesante y siempre genera movimiento e interés en el oyente. No requieren de un despliegue técnico o variedad de efectos con los instrumentos, sin embargo, la propuesta de producción del sonido y sus relaciones tímbricas son elementos que llaman la atención en cada una de las obras.

Después de los análisis estructurales y estéticos, se ha conocido una expresión musical rica y meditada en aspectos de lógica musical, lógica matemática y lógica contextual; esto último, en concordancia de los escritos literarios con la música. La obra de Pitombeira presenta una clara influencia de Bela Bartok e Igor Stravinsky, expuestos en sus ideas rítmicas y contrastantes, logrando que los instrumentos -en este caso, tres- mantengan su identidad sonora y aún así logren conversar armónicamente. Una obra como Fantasia sobre a muié rendêra deja una clara influencia de su compatriota, el compositor Mozart Camargo Guarnieri, quien dedicó su vida a la música brasilera e influyó fuertemente en las generaciones posteriores a su muerte. La música de Pitombeira, muy calculada y a la vez sencilla, invita a explorar un nuevo nacionalismo y una nueva manera de conocer las posibilidades musicales en contraste con las ideas academicistas y las posibilidades del folclor, yuxtapuestas en otras artes.

En palabras del compositor, es muy probable que ejerza alguna influencia en sus estudiantes de pregrado y posgrado (Pitombeira, 2019), aspecto que es seguro, dados los aportes que ha realizado a lo largo de su carrera y de su experticia en el campo de la composición y la investigación. 


\section{Referencias}

Assis, Machado de, J. R. (1873). Histórias da meia-noite. São Paulo, Brasil: LEL.

Benedetti, E. [Enrico Benedetti] (24 de febrero de 2015). A-Trio Pitombeira [Archivo de video]. Recuperado de https://www.youtube.com/watch?v=vMnA_rYOEtk

de Quadros Junior, A. \& Volp, C. (2005). Forró Universitário: a tradução do forró nordestino no sudeste brasileiro. Revista de Educacion Fisica UNESP, 11(2), 127-130.

Correa Suárez, K. \& Sheldrick, B. (2019). Repertorio latinoamericano para clarinete, viola y piano: catálogo con comentarios. Ricercare, (10), 55-82. https://doi. org/10.17230/ricercare.2018.10.3

Literatura Brasilera. (1994). Obra completa de Machado de Assis (Vol. II). Rio de Janeiro, Rio de Janeiro, Brasil: Nova Aguilar. Recuperado de http://noticias.universia. com.br/net/files/2015/3/27/flor-anonima-machado-de-assis.pdf

Literatura Digital. (2018). Ao Acaso (Crônicas da Semana). Recuperado de https:// www.literaturabrasileira.ufsc.br/documentos/?action=midias\&id=209677

Mariz, V. (1921). Heitor Villa-Lobos: El Nacionalismo Musical Brasilero. Mexico: Editorial Siglo XXI.

Pitombeira, L. (2010). Fantasia sobre a muie renderá op. 1f. Recuperado de http:// www.pitombeira.com

Pitombeira, L. (2015). Praineiras op. 200 para clarinete, viola y piano. Recuperado de http://www.pitombeira.com

Pitombeira, L. (2016). Brasiliana op 173c para clarinete, viola y piano. Recuperado de http://www.pitombeira.com

Pitombeira, L. (2017). Compositores de hoje (Grabado por Trio Praineiras) [Spotify APP].

Praineiras, T. (Diciembre de 2017). Spotyfy. Obtenido de https://open.spotify.com/ album/7kJzzvk09qoLmoPtT4IL9z?si=6_ak1jfeT5aOtrloefj3NQ

PEAO. [Peao2007). (19 de mayo de 2009). Volta Seca - Mulher Rendeira (versão original) [Archivo de video]. Recuperado de https://youtu.be/yxjWPUJmVvA

Siqueira, J. (1981). 0 sistema modal na música folclórica do Brasil (3.a ed.). Rio de Janeiro, Brasil: Editora Americana.

BodartPreciosidades. [BodartPreciosidades]. (3 de marzo de 2013). Syntagma

- Algodão [Archivo de video]. Recuperado de https://www.youtube.com/ watch? $v=09 \mathrm{LPH} 4 \mathrm{Hsu} 9 \mathrm{~s}$ 